\title{
A novel microcosm to identify inherently competitive microorganisms with the ability to mineralize phytate in solum
}

\author{
Sabrina M. Pittroff ${ }^{1}$, Stefan Olsson ${ }^{2,6,{ }^{*}}$, Ashlea Doolette ${ }^{5}$, Ralf Greiner ${ }^{4}$, Alan E. Richardson ${ }^{3}$, \\ Mette Haubjerg Nicolaisen ${ }^{1, *}$
}

1 Microbial Ecology and Biotechnology, Department of Plant and Environmental Sciences, Faculty of Science, University of Copenhagen, Thorvaldsensvej 40, 1871 Frederiksberg C, Denmark

2 State Key Laboratory for Ecological Pest Control of Fujian and Taiwan Crops, College of Plant Protection, Fujian Agriculture and Forestry University, Fuzhou 350002, China

3 CSIRO Agriculture and Food, PO Box 1700, Canberra, ACT, 2601, Australia

4 Department of Food Technology and Bioprocess Engineering, Max Rubner Institut, Karlsruhe, German

5 School of Agriculture, Food and Wine, Waite Research Institute, The University of Adelaide, Waite Campus Urrbrae, SA, 5064 Australia 6 Plant Immunity Center, Haixia Institute of Science and Technology, Fujian Agriculture and Forestry University, Fuzhou 350002, China

H I G H L I G H T S

- A novel microcosm for identifying phytatedegrading soil microbes is introduced.

- Phytate microcosms recruited different microbial profiles when compared to controls. - Microbial populations recruited by phytate showed phosphatase activity in vitro.

- Streptomyces were indicated as inherently competitive in solum utilizers of phytate.

\section{ARTICLE INFO}

Article history:

Received September 30, 2020

Revised January 9, 2021

Accepted March 29, 2021

\section{Keywords:}

Myo-inositol hexakisphosphate (phytate)

Soil microcosm

Soil microbial ecology

Biofertilizers

Alkaline phosphatase

$\beta$-propeller phytase (BPP)

\section{GRAPHICAL ABSTRACT}

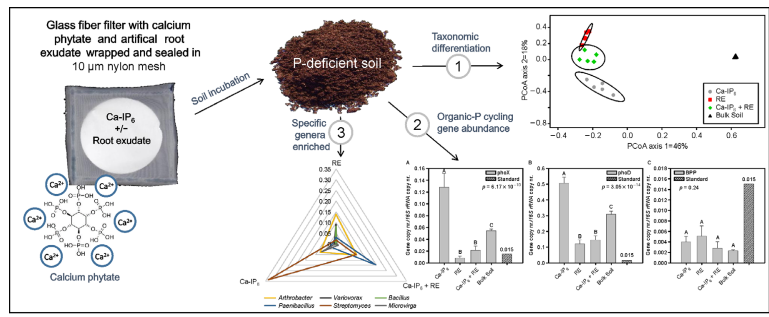

A B S T R A C T

Fertilizer phosphorus $(\mathrm{P})$ is a finite resource, necessitating the development of innovative solutions for $P$ fertilizer efficiency in agricultural systems. Myo-inositol hexakisphosphate (phytate) constitutes the majority of identified organic $\mathrm{P}$ in many soil types and is poorly available to plants. Incorporating phytase-producing biofertilizers into soil presents a viable and environmentally acceptable way of utilizing $\mathrm{P}$ from phytate, while reducing the need for mineral $\mathrm{P}$ application. A deeper understanding of the microbial ecology in relation to degradation of phytate under natural soil conditions is however needed to obtain successful biofertilizer candidates able to compete in complex soil environments. Here we present the development of a microcosm for studying microbial communities able to colonize and utilize Ca-phytate hotspots in solum. Our results provide evidence that the recruited microbial population mineralizes Ca-phytate. Furthermore, quantification of bacterial genes associated with organic $\mathrm{P}$ cycling in alkaline soils indicated that the phosphatases PhoX and PhoD may play a larger role in phytate mineralization in soil than previously recognized. Amplicon sequencing and BioLog ${ }^{\circledR}$ catabolism studies show that hotspots containing Ca-phytate, recruited a different set of microorganisms when compared to those containing an addition of $\mathrm{C}$ source alone, with the genus Streptomyces specifically enriched. We propose that Streptomyces represents an hitherto unexplored resource as $\mathrm{P}$ biofertilizer with competitive advantage for utilizing CaPhy in an inherently competitive soil environment. We further conclude that the use of our newly designed microcosm presents an innovative approach for isolating soil microorganisms with the potential to degrade precipitated phytate in solum.

(C) Higher Education Press 2021

\footnotetext{
* Corresponding authors

E-mail address: stefan@olssonstefan.com (S. Olsson); meni@plen.ku.dk (M.H. Nicolaisen)
} 


\section{Introduction}

Biofertilizers are considered to be a cost effective and ecofriendly alternative to chemical fertilizers that can be used in the place of, or in combination with, conventional fertilizers as a means to enhance soil fertility (Singh et al., 2011; Bhardwaj et al., 2014). One obstacle that is consistently encountered is the translation of desirable traits identified from in-vitro studies to consistent performance or persistence of those traits in soil (Richardson et al., 2001; Rengel and Marschner, 2005). One of the key challenges is the complex and competitive nature of soils, which harbor highly diverse and abundant communities of indigenous microorganisms. This preexisting soil ecosystem represents a barrier for the establishment of specific introduced strains of interest (Malusá et al., 2012; Raynaud and Nunan, 2014). While studies based on pure cultures or with a few interacting strains have revealed important insight into the physiology of soil microorganisms, there is an overwhelming need to better understand functional capacities in real soil systems (de Menezes et al., 2017). This limited understanding of soil ecology and function represents a major impediment to the effectiveness of biofertilizers that are expected to perform specific tasks under these complex conditions. Focus on new isolation techniques to obtain in solum-compatible microorganisms with plant-growth-promoting capabilities and improved in-field performance has therefore increased (Cuong et al., 2011; Ghodsalavi et al., 2017), and improved translational power from laboratory to field has been observed when using in situ mimicking microcosms for isolation of microbial inoculants (Nicolaisen et al., 2018).

Organic $\mathrm{P}$ in soil is a significant pool of $\mathrm{P}$ that is currently not considered in modern agricultural production (Cordell et al., 2011; Cordell et al., 2011; Stutter et al., 2012; George et al., 2016). The major identifiable form of organic $P$ found in soils is phytate, or myo-inositol 1,2,3,4,5,6-hexakisphosphate $\left(\mathrm{IP}_{6}\right)$. It represents a substantial pool of $P$ in soils that is largely not available to plants (Turner et al., 2002; Turner et al., 2007; Yan et al., 2014). Phytate reacts readily in soil through adsorption reactions, and has been shown to form precipitates with iron and aluminum ( $\mathrm{Fe}, \mathrm{Al}$ ) in acidic soils or calcium (Ca) in alkaline soils (Jackman, 1951; von Wandruszka, 2006; Gerke, 2015). Despite being heavily bound in soils, utilization of inositol phosphate by plants via the presence of soil microorganisms has been reported (Richardson et al., 2001). Bacteria and fungi have been shown to produce enzymes that can hydrolyze phytate to release orthophosphate (Richardson and Hadobas, 1997; Idriss et al., 2002; Lim et al., 2007; Huang et al., 2009). One class of these enzymes found in bacteria are $\beta$-propeller phytases (BPPs), which have been shown to specifically hydrolyze phytate under neutral and alkaline conditions (Shin et al., 2001; Turner et al., 2007; Shim and Oh, 2012). This class has a narrow substrate-specificity toward phytate, and various crystal structures analyses have shown that the BPP phytase active site accommodates $\mathrm{Ca}$ bound phytate (Ca-Phytate) (Kerovuo et al., 2000; Shin et al.,
2001; Oh et al., 2004) and some studies suggest that solubilization of the Ca-phytate is not necessary prior to mineralization (Oh et al., 2006; Kim et al., 2010). To-date, the BPP is the only microbial phytase shown to work under alkaline conditions. More general phosphatases, PhoD and PhoX, have also been shown to function optimally under neutral-alkaline conditions and have recently been predicted to contribute to increased phytate mineralization in soil (Ragot et al., 2017; Neal et al., 2017). This likely via accommodating lower order myo-inositol phosphates $\left(\mathrm{IP}_{5}-\mathrm{IP}_{1}\right)$, though their activity toward phytate or Ca-phytate has, to our knowledge, not been explicitly tested. The existence of these enzymes suggests a potential for development of biofertilizers using bacteria adapted to alkaline soil conditions with selective advantages for degrading Ca-phytate and lower order myoinositol phosphates.

In the present study, a soil-based microcosm was developed to study microbial communities participating in soil organic $P$ cycling and provide an isolation platform for selection of biofertilizer candidates. To enrich for competitive soil community microorganisms capable of functioning within the pre-existing soil ecology, we perform the enrichment in solum using $\mathrm{Ca}$-phytate $\left(\mathrm{Ca}-\mathrm{IP}_{6}\right)$ hotspots as bait. We test the hypotheses that: 1) Ca-phytate hotspots recruit distinct populations compared to regions without Ca-phytate and 2) Ca-phytate hotspots recruit bacterial populations with increased phytase activity, and an increased potential for organic $\mathrm{P}$ cycling in general. Amplicon sequencing of the 16S rRNA gene and catabolism fingerprinting using BioLog® were used to obtain phenotypic and taxonomic profiles of the hotspot communities. Quantification of bacterial genes associated with organic $\mathrm{P}$ cycling in alkaline soils (phoX, phoD, and $B P P$ ) was done using $\mathrm{qPCR}$, and finally, phytase activity assay and myo-inositol phosphate quantification post-incubation was used to measure the functional profile of the hotspot communities.

\section{Materials and methods}

\subsection{Soil characterization}

The soil was a sandy loam collected from a long-term nutrient depletion trial (LTNDT, $\mathrm{N}_{1} \mathrm{~K}_{1}$ ) deprived of $\mathrm{P}$ fertilizers since 1964 (van der Bom et al., 2017, 2018, 2019a, 2019b). The soil consisted of clay $164 \mathrm{~g} \mathrm{~kg}^{-1}$, silt $173 \mathrm{~g} \mathrm{~kg}^{-1}$, fine sand $333 \mathrm{~g} \mathrm{~kg}^{-1}$ and coarse sand $312 \mathrm{~g} \mathrm{~kg}^{-1}$. It further contained $17 \mathrm{~g} \mathrm{~kg}^{-1}$ of soil organic matter, and was classified as a Luvisol in the FAO system. Total soil $\mathrm{C}$ and $\mathrm{N}$ was $12.3 \mathrm{~g} \mathrm{C} \mathrm{kg}^{-1}$ and $1.65 \mathrm{~g} \mathrm{~N} \mathrm{~kg}^{-1}$, respectively, with a $\mathrm{C}: \mathrm{N}$ ratio of 7.6 . Available $\mathrm{K}$ (ammonium-acetate-exchangeable $\mathrm{K}$ ) was $134.8 \mathrm{mg} \mathrm{kg}^{-1}$; available Mg (ammonium-acetate-exchangeable $\mathrm{Mg}$ ) was $66.0 \mathrm{mg} \mathrm{kg}^{-1}$. Cation concentrations in a 1:10 soil:water suspension was $\mathrm{Ca} 19.8 \mathrm{mg} \mathrm{kg}^{-1}$, Fe $22.7 \mathrm{mg} \mathrm{kg}^{-1}, \mathrm{~K} 29.5$, Mn $2.7 \mathrm{mg} \mathrm{kg}^{-1}$, Si $51.9 \mathrm{mg} \mathrm{kg}^{-1}$.

Soil $\mathrm{pH}$ and analysis of orthophosphate content were 
determined by independent laboratory analysis in triplicate (OK Laboratorium for Jordbrug, Denmark). The extractable Olsen $\mathrm{P}$ and $\mathrm{pH}\left(\mathrm{CaCl}_{2}\right)$ for the soil were $6.5 \pm 1.5 \mathrm{mg} \mathrm{kg}^{-1}$ and $\mathrm{pH} 6.13 \pm 0.04$, respectively.

To evaluate the composition of the organic $\mathrm{P}$ pool in the soil, $P$ content was further analyzed by nuclear magnetic resonance (NMR). $P$ was extracted from the soil with sodium hydroxide-ethylenediaminetetra-acetic acid ( $\mathrm{NaOH}-\mathrm{EDTA})$ using standard procedures for NMR analysis (Doolette et al., 2017). For quantification of $P$ into specific classes the ${ }^{31} \mathrm{P}$ NMR spectra were integrated across four broad chemical regions: phosphonate $(\delta 18-22 \mathrm{ppm})$, orthophosphate and phosphomonester $\mathrm{P}(\delta 6.5-3.5 \mathrm{ppm})$, phosphodiester $\mathrm{P}$ ( $\delta 2$ to $-1 \mathrm{ppm}$ ) and pyrophosphate ( $\delta-4.5$ to $-5.5 \mathrm{ppm})$. Due to several overlapping peaks within the orthophosphate and phosphomonoester region of the ${ }^{31} \mathrm{P}$ NMR spectra, the relative concentrations of $P$ species were determined using the spectral integration and deconvolution fitting technique described in McLaren et al. (2015).

2.2 Set-up and employment of the Ca-phytate soil microcosm baiting system

A microcosm employing a 'bait' source of interest, in this case Ca-phytate, was designed to enable studying the colonization of hotspots in solum with the long-term goal of using the microcosm as an isolation platform to obtain phytate degrading microorganisms inherently successful under competitive soil conditions. Figure 1 visually represents the designed hotspot - microcosm system.

The Ca-phytate $\left(\mathrm{Ca}-\mathrm{IP}_{6}\right)$ 'bait' substrate used was synthesized with modifications based on Hoff-Jøorgensen et al. (1944) by adding autoclaved calcium chloride $\left(\mathrm{CaCl}_{2}\right)$ into filter sterilized sodium ( $\mathrm{Na}$ )-phytate salt $(0.2 \mu \mathrm{m}$ filter) at a 1:6.5 molar ratio and adjusting the $\mathrm{pH}$ to 7 using sterile $2 \mathrm{M}$
$\mathrm{NaOH}$. Three wash steps were included in order to eliminate contaminating un-precipitated salts before speed vacuum dehydration. The purity of the phytic acid-Na salt source (BHD biochemical, No 38045) was confirmed via $\mathrm{P}^{31}$ NMR analysis as well as colorimetric testing to be phytic acid with no contaminating lower order inositols (>99\% purity) and negligible free orthophosphate. The resulting Ca-phytate was confirmed via ICP analysis to contain a 1:1 ratio of $\mathrm{Ca}$ : P. A volume of $200 \mu \mathrm{L}$ of a $5 \%$ Ca-phytate slurry in water was used to impregnate a $25 \mathrm{~mm}$ Whatman ${ }^{\mathrm{TM}}$ glass microfiber filter GF/C ${ }^{\mathrm{TM}}$ (GFF) and left to dry under sterile conditions. This provided a total amount of $10 \mathrm{mg} \mathrm{Ca-phytate} \mathrm{on} \mathrm{each}$ filter. Two-hundred $\mu \mathrm{L}$ sterile water was used in hotspots lacking Ca-phytate. Agar drops containing an artificial root exudate (RE) solution or water was then added dropwise on top of the filters ( 10 drops of $5 \mu \mathrm{L}$ per filter using agar solutions at $\sim 50^{\circ} \mathrm{C}$ ) around the GFF filter surface and left to solidify under a laminar flow hood. The RE-nutrient solution consisted of D-glucose (50 mM), D-fructose (50 mM), sucrose (50 mM), succinic acid (25 mM), L-malic acid (25 mM), L-arginine (12.5 $\mathrm{mM})$, L-serine (12.5 mM), L-cysteine (12.5 mM), $\mathrm{CaCl}_{2}(27$ $\mathrm{mM}), \mathrm{NH}_{4} \mathrm{NO}_{3}(30 \mathrm{mM}), \mathrm{KCl}(67 \mathrm{mM}), \mathrm{MgSO}_{4}(2 \mathrm{mM}), \mathrm{FeSO}_{4}$ $(36 \mu \mathrm{M}), \mathrm{MnSO}_{4}(45 \mu \mathrm{M})$. The treated GFFs were finally wrapped and sealed in $50 \mu \mathrm{m}$ sterile mesh (Sintab Product $A B$, fabric 6111-005043) and incubated in soils with water added to $50 \%$ water-holding-capacity ( $14 \%)$.

The experimental setup included the following hotspot

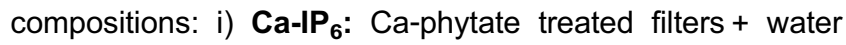
agar drops, ii) RE: water treated filters + root-exudate agar drops iii) $\mathbf{C a}_{\mathbf{I}} \mathbf{P}_{\mathbf{6}}+\mathbf{R E}$ : Ca-phytate treated filters + rootexudate agar drops. The hotspots were completely embedded in LTNDT soil and incubated for 5 days at $20^{\circ} \mathrm{C}$. After incubation, hotspots were removed and cut free from the surrounding mesh-bag using flame-sterilized scissors and forceps.

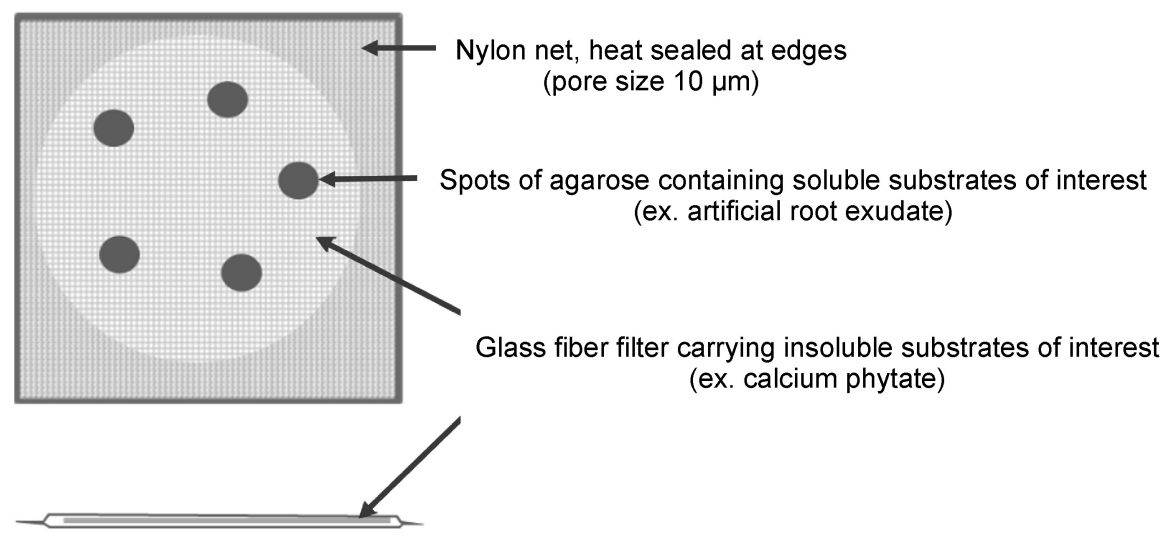

Fig. 1 In-soil hotpot system used for selecting soil bacterial strains attracted to precipitated phytate. The baiting hotspots are composed of a glass fiber filters amended with calcium phytate (or water). Subsequently, spots of agar containing root exudate medium (or water) are applied. Finally, the microcosm is wrapped in sterile mesh and is heat-sealed along all edges in order to exclude soil particles. 
2.3 Quantification of myo-inositol phosphates recovered from hotspot GFFs by high-performance liquid chromatography (HPLC)

Three hotspot GFFs retrieved from each of the microcosm treatments as well as two non-inoculated controls were extracted by shaking for $30 \mathrm{~min}$ in $5 \mathrm{~mL} 0.6 \mathrm{M} \mathrm{HCl}$ at room temperature. Extracts were filtered using a $0.22 \mu \mathrm{m}$ filter. Subsequently, the solutions were diluted 1:25 with water and passed through a column containing AG1-X8, 100-200 mesh resin. The column was washed with 10 volumes (the column volume) of water and 10 volumes of $25 \mathrm{mM} \mathrm{HCl}$. Phytate was finally eluted with 5 volumes of $2 \mathrm{M} \mathrm{HCl}$. The eluate was concentrated in a vacuum evaporator to dryness and the residue was dissolved in $1 \mathrm{~mL}$ water. Finally, $20 \mu \mathrm{L}$ of the samples were subject to HPLC (Ultrasep ES 100 RP18; $2 \times 250 \mathrm{~mm}$ ) to determine phytate concentration and presence of lower order myoinositol phosphate derivatives. The column was run at $45^{\circ} \mathrm{C}$

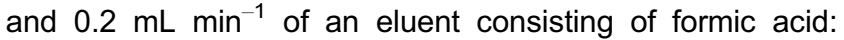
methanol:water:tetrabutylammonium hydroxide (44:56:5:1.5 $\mathrm{v} / \mathrm{v}), \mathrm{pH} 4.25$, as described by Sandberg and Ahderinne (1986). Phytic acid, dodecasodium salt hydrate (Aldrich, $27,432-1)$ was used as a standard.

\subsection{Catabolism fingerprinting of the hotspot extracts by} BioLog $\circledast$ Eco plates

Samples for BioLog® ECOplate (BIOLOG, Hayward, CA) catabolism analysis as well as phytase hotspot activity (described in subsection 2.5) were performed in triplicate, each replicate consisting of two hotspot GFFs combined across treatments to obtain sufficient biomass for the assay. Filters were extracted from soil as described above, and the hotspot GFFs were immersed into $11 \mathrm{~mL}$ of $0.9 \% \mathrm{NaCl}$ and shaken at 150 RPM (KS250basic, IKA labortechnik) for $1 \mathrm{~h}$ at room temperature with intermittent vortexing.

For BioLog ${ }^{\circledR}$ ECOplates, a subsample was taken and nystatin was added to a final concentration of $50 \mu \mathrm{g} \mathrm{mL}^{-1}$, before aliquoting onto the plates in triplicate (one ECOplate per sample, $100 \mu \mathrm{L}$ per well). The BioLog $\circledast E$ ECOplates were incubated at $15^{\circ} \mathrm{C}$ (to mimic Danish spring time temperatures) in the dark and tetrazolium violet oxidation (color development) was measured at $590 \mathrm{~nm}$ using an Epoch (BioTek) plate reader every $6-12 \mathrm{~h}$ for $240 \mathrm{~h}$ (10 days). Several time points were analyzed in order to follow the color development, however, the time point chosen for presentation and statistical analysis was the reading corresponding to half of the average well color development (AWCD), which was $144 \mathrm{~h}$ for all treatments. Absorbance levels were normalized to the control well containing only microcosm extract and water. Data was visualized by principal component analysis (PCA). Statistical relevance was tested using a one-way ANOSIM (nonparametric) employing Euclidean distance measures. Posthoc ANOSIM pairwise comparisons identified specific treatments contributing to significance at $p<0.05$.

\subsection{Phytase activity of the hotspot extracts}

For phytase activity assays, filters in $0.9 \% \mathrm{NaCl}$ (described in subsection 2.4) was used for measuring enzyme activity. Filters were subjected to mechanical lysis to recover the entire microbial biomass associated with the hotspot. This was considered the cell-associated enzyme fraction. The phytase assay used was modified from standard phytate assay (Heinonen and Lahti, 1981), as it utilized precipitated Caphytate at $\mathrm{pH} 7$, instead of soluble Na-phytate at $\mathrm{pH} 5$. The Ca-phytate was prepared by adding filter-sterilized myoinositol hexakisphosphate dodecasodium salt (Na-lHP; Sigma P-0810) suspended in distilled water to sterile $1.5 \mathrm{M}$ $\mathrm{CaCl}_{2}$, and bringing the $\mathrm{pH}$ up to 7 using sterile $\mathrm{NaOH}$. The resulting precipitate was washed in sterile distilled water and suspended to an appropriate concentration for immediate use. The hotspot filters were suspended in a total of $1 \mathrm{~mL}$ $0.9 \% \mathrm{NaCl}$ in Lysing Matrix $\mathrm{E}$ tubes containing glass beads (MP Biomedicals) and beaten 3 times at 1 oscillation/s frequency (FastPrep-24, MP Biomedicals). The samples were then centrifuged at $10000 \times g$ for $10 \mathrm{~min}$ at $4^{\circ} \mathrm{C}$ and the aqueous fraction used immediately in phytase assays. Orthophosphate released in the phytase assays was measured in a 96-well microtiter plate using malachite green (MG) colorimetry as described by D'Angelo et al. (2001). Briefly, 30 $\mu \mathrm{L}$ of MG reagent $\left(1 \mathrm{~g} \mathrm{~L}^{-1}\right.$ polyvinylalcohol, $1.2 \mathrm{~g} \mathrm{~L}^{-1} \mathrm{H}_{3} \mathrm{BO}_{3}$, $34.66 \mathrm{~g} \mathrm{~L}^{-1}\left(\mathrm{NH}_{4}\right)_{2} \mathrm{MoO}_{4}, 476 \mathrm{~mL} \mathrm{~L}^{-1} 10 \mathrm{~N} \mathrm{H}_{2} \mathrm{SO}_{4}, 0.229 \mathrm{~g} \mathrm{~L}^{-1}$ malachite green) was added to each well containing $240 \mu \mathrm{L}$ of the crude enzyme extract. The assay was incubated for $24 \mathrm{~h}$ at room temperature as described by Tang et al. (2006). Assay conditions included the presence and absence of Ca-phytate salt precipitate $\left(20 \mathrm{mM} \mathrm{Ca}-\mathrm{IP}_{6}\right.$ (as described above) and MOPS $(20 \mathrm{mM})$ buffered at $\mathrm{pH}$ 7.2. Absorbance was measured at $620 \mathrm{~nm}$ after allowing $30 \mathrm{~min}$ color development. Orthophosphate standards from 0 to $40 \mu \mathrm{M}$ were used as a standard curve. Technical duplicates were run on all samples and controls. Extracts assayed in the absence of substrate were included to account for residual orthophosphate or phytate degradation under the assay conditions and were subtracted from the experimental values. The resulting data were normalized to bacterial $16 \mathrm{~S}$ rRNA gene copy number as determined by qPCR (as outlined below).

2.6 DNA extraction and quantitative PCR (qPCR) of bacterial $16 \mathrm{~S}$ rRNA and functional genes

Two GFFs were collected from each treatment and washed in a $5 \mathrm{~mL}$ aliquot of $0.9 \% \mathrm{NaCl}$ as described above. Quintuplicate samples were then taken from the pooled extract for DNA extraction. A phenol-chloroform protocol for DNA extraction was employed as described previously (Nicolaisen et al., 2008), with the exception that all samples were incubated overnight at $4^{\circ} \mathrm{C}$ during PEG precipitation. Primer sequences used for quantification of the bacterial 16S rRNA gene, the alkaline phosphatase genes $p h o D$ and phoX; and the $\beta$ propeller phytase gene $(B P P)$ are listed in supplementary 
materials (Table S1). Absolute quantification was performed using plasmid-based standard curves developed by Hao et al. (2020). All reactions were performed on the AriaMX® using the Brilliant III UltraFast QPCR Master Mix SYBR® Green (Agilent technologies, USA). Each $25 \mu \mathrm{L}$ reaction contained 2 $\mu \mathrm{L}$ of the undiluted microcosm DNA extract, $1 \mu \mathrm{g} \mu \mathrm{L}^{-1} \mathrm{BSA}$ (New England Biolabs ${ }^{\circledR}$ Inc., UK), $1 \times$ mastermix and $0.4 \mu \mathrm{M}$ primer. Thermal profile for BPP primers was carried out as follows: $3 \mathrm{~min}$ at $95^{\circ} \mathrm{C}$ followed by 5 cycles touch-down starting at $65^{\circ} \mathrm{C}$ and decreasing $0.4^{\circ} \mathrm{C}$ per cycle, after which 35 cycles of $30 \mathrm{~s}$ at $95^{\circ} \mathrm{C}, 30 \mathrm{~s}$ at $63^{\circ} \mathrm{C}, 30 \mathrm{~s}$ at $72^{\circ} \mathrm{C}$, and $10 \mathrm{~s}$ at $82^{\circ} \mathrm{C}$ were carried out. The thermal profile for all other primers was as follows: $3 \mathrm{~min}$ at $95^{\circ} \mathrm{C}$ followed by 40 cycles of $20 \mathrm{~s}$ at $95^{\circ} \mathrm{C}, 30 \mathrm{~s}$ at $58^{\circ} \mathrm{C}$. Fluorescence was measured at the end of the final step in each recurring cycle. A melting curve analysis was performed in each run to assist in quality control checking for each reaction. The absolute abundance of specific functional genes was calculated based on standard curves generated by 10 -fold serial dilutions of standard plasmids and was normalized to the $16 \mathrm{~S}$ rRNA gene (i.e., gene copy number/16S rRNA gene copy number; Hao et al. (2020)). The efficiency of the standard curves ranged from $76 \%$ to $83 \%$, indicating a potential underestimation in this assay. All samples were run using 5 independent biological replicates extracted in triplicate. For absolute numbers ( $p h o X$, $P h o D, B P P)$ a Kruskal-Wallis test for non-normally distributed data was used, followed by Mann-Whitney pairwise comparisons. For normalized data (i.e., gene/16S rRNA copy number), a square root transformation (sqrt (value +1$)$ ) or BoxCox transformation $\left(Y^{-\lambda}=1 / Y^{\lambda}\right)$ was performed to achieve normality prior to performing one-way ANOVA. The $P$-values reported are either as Fishers ANOVA, where equal variance is followed, or by a Welche's ANOVA in the case of unequal variance as tested by Levene's test for homogeneity of variance based on means. Either a Tukey's or Games-Howell (in the case of unequal variance) pairwise comparison was used post-hoc to identify specific treatments contributing to the ANOVA significance.

2.7 Taxonomic identification and comparative analysis by $16 \mathrm{~S}$ rRNA amplicon sequencing

All samples were sequenced by Macrogen Inc. (Seoul, Rep. of Korea) using aliquots of the above-mentioned DNA extracts (see subsection 2.6). In short, the variable region V3-V4 of the 16S rRNA gene was amplified by PCR using the primer pair 341F (5'-CCTAYGGGGRBGCASCAG-3') and 806R (5'-GGACTACNNGGGTATCTAAT-3') and sequenced using a Paired-end Illumina MiSeq platform. A total of 6087974 16S rRNA gene sequence reads were obtained. After quality filtering and removal of adaptors and ambiguous nucleotides, 2686025 merged pairs were obtained with an average PHRED score of 45 . Sequences were analyzed using CLC Genomics Workbench with the Microbial Genomics Module (Qiagen). Sequence adaptors were removed and trimming was performed to exclude low quality DNA (quality score limit 0.05 ) and sequences with ambiguities above 2 . Reads less than 5 nucleotides were discarded before merging forward and reverse amplicon reads with default values and standardizing sequence lengths. The partial 16S rRNA gene sequences were then clustered and assigned to operational taxonomic units (OTUs) with a $97 \%$ similarity using the Greengenes database (DeSantis et al., 2006) with allowance of new OTU creation. During OTU clustering suspected chimeras were removed and finally, taxonomy including chloroplast or mitochondria were filtered from the sequence list. The sequence reads clustered into 1434 known OTUs, as well as 550 de novo OTUs; yielding a total of 1984 OTUs. Rarefaction analysis supports that the sequencing depth captured sufficient diversity of the bacterial communities in the microcosm and bulk soil samples, as seen by apparent asymptote in the rarefaction curves (Supplementary Fig. S1). The a-diversity and Principal Coordinates Analysis (PCoA) were performed with the software PAST v.2.17 using BrayCurtis dissimilarity matrices at an OTU level. Furthermore, pairwise similarity percentages (SIMPER) were used to determine the taxa contribution to the average dissimilarity between treatments (Bray-Curtis calculated) (Clarke, 1993) and were ultimately used to create a Venn diagram; using VENNY (Oliveros, 2007). The calculated a-diversity, represented by Shannon, and Chao-1 estimations, was compared using ANOVA and post-hoc Tukey test. Rarefication to the lowest read number using RStudio ( $V$ 1.1.456) software was performed before testing for statistical significance of the overall difference in microbial community composition ( $\beta$ diversity) by one-way NP-MANOVA (PERMANOVA) on BrayCurtis dissimilarity matrix with 9999 permutations in PAST v.2.17.

\subsection{Accession numbers}

Sequences were deposited in the European Nucleotide Archive (ENA) database under the study accession number PRJEB39274.

\section{Results}

\section{1 $\mathrm{P}$ content of soil used for the microcosm}

$\mathrm{P}^{31} \mathrm{NMR}$ analysis of the LTNDT soil showed a total amount of extractable $P$ of $293 \mathrm{mg} \mathrm{kg}^{-1}$. Organic $P$ accounted for approximately half of the total $P$ and consisted primarily of $\alpha-$ and $\beta$-glycerophosphate (likely derived from the alkaline hydrolysis of lipids in the soil sample), inositol phosphates as well as uncharacterized monoester $P$, whereas no phosphonate or diesters were detected. Of the inositol phosphates, myo-inositol hexakisphosphate (phytate or $\mathrm{IP}_{6}$ ) accounted for $27 \mathrm{mg} \mathrm{kg}^{-1}$, corresponding to $9.3 \%$ of the total soil P (Supplementary Fig. S2). 
3.2 Recovery of myo-inositol phosphate (phytate) from hotspots

Extraction from the filter hotspots and quantification by HPLC represented a myo-inositol phosphate recovery efficiency of 95.5\%, compared with the non-incubated GFFs as reference samples. The soil-incubated microcosms containing $\mathrm{Ca}-$ phytate plus root exudate $\left(\mathrm{Ca}-\mathrm{IP}_{6}+\mathrm{RE}\right)$ showed a significant decrease in HPLC-detectable myo-inositol phosphate with quantities averaging $1.76 \mathrm{mM}$ (83\% of initial, post-hoc MannWhitney $p<2.4 \times 10^{-4}$, Table 1 ), whereas the soil-incubated Ca-phytate hotspot $\left(\mathrm{Ca}-\mathrm{IP}_{6}\right)$ alone showed no detectable loss of myo-inositol phosphate.

Table 1 Myo-Inositol phytate substrate remaining on the microcosm GFF pre and post in-soil incubation.

\begin{tabular}{llll}
\hline $\begin{array}{l}\text { Microcosm } \\
\text { treatment }\end{array}$ & Soil incubation & $\mathrm{IP}_{6}(\mathrm{mM})$ & $\operatorname{SEM}(n=3)$ \\
\hline Ca-IP $_{6}$ & no & 2.115 & 0.014 \\
$\mathrm{RE}$ & no & nd & - \\
$\mathrm{Ca}-\mathrm{IP}$ & yes & 2.126 & 0.025 \\
$\mathrm{RE}$ & yes & nd & - \\
Ca-IP $_{6}+\mathrm{RE}$ & yes & $1.7655^{*}$ & 0.041
\end{tabular}

Data obtained from soil-incubated samples were based on biological triplicates and non-incubated samples were tested in biological duplicates. Statistical relevance was tested using the non-parametrical Kruskal-Wallis test. Microcosms treatments were as follows: calcium phytate alone (Ca-IP6), root-exudate alone (RE), and calcium phytate combined with root-exudate (Ca-IP6 + RE). * Significant decrease in $\mathrm{IP}_{6}$ detected when compared to non-soil incubated and incubated Ca- $\mathrm{IP}_{6}$ controls (post-hoc Mann-Whitney; $P<2.4 \times 10^{-4}$ ), nd $=$ non-detectable.

Soil incubated filters containing only RE yielded no detectable substrate regardless of their incubation status, indicating no soil-originating contamination of $\mathrm{Ca}-\mathrm{IP}_{6}$ presence. No lower order myo-inositol phosphate products were detected in any of the treatments, despite the capacity of the HPLC assay being able to detect lower order myo-inositol phosphates $\mathbb{I P}_{5}-\mathbb{I P}_{3}$.

\subsection{Orthophosphate liberation by crude enzyme hotspot} extracts

Crude activity of the enzyme extracts from the microcosms harboring the Ca-phytate hotspot showed release of orthophosphate that was in the order of $23.6 \pm 13.2 \mathrm{nmol}$ and $54.4 \pm$ $36.5 \mathrm{nmol}$ of $\mathrm{P}$ from the $\mathrm{Ca}-\mathrm{IP}_{6}$ and the $\mathrm{Ca}-\mathrm{IP}_{6}+\mathrm{RE}$ hotspots respectively. No detection of released orthophosphate was seen in the crude extract acquired from the RE microcosm. To account for the varied bacterial recruitment across the treatments, these values were normalized to $16 \mathrm{~S}$ rRNA gene copy numbers (i.e., nmol P/16S rRNA gene copy number) showing comparable $P$ release per 16s rRNA
(Fig. 2). While no statistical difference was seen between treatments $\left(\mathrm{Ca}-\mathrm{IP}_{6}\right.$ and $\left.\mathrm{Ca}-\mathrm{IP}_{6}+\mathrm{RE}\right)$, it is apparent that no detectable orthophosphate was released from the crude extracts originating from microcosms lacking Ca-phytate (RE).

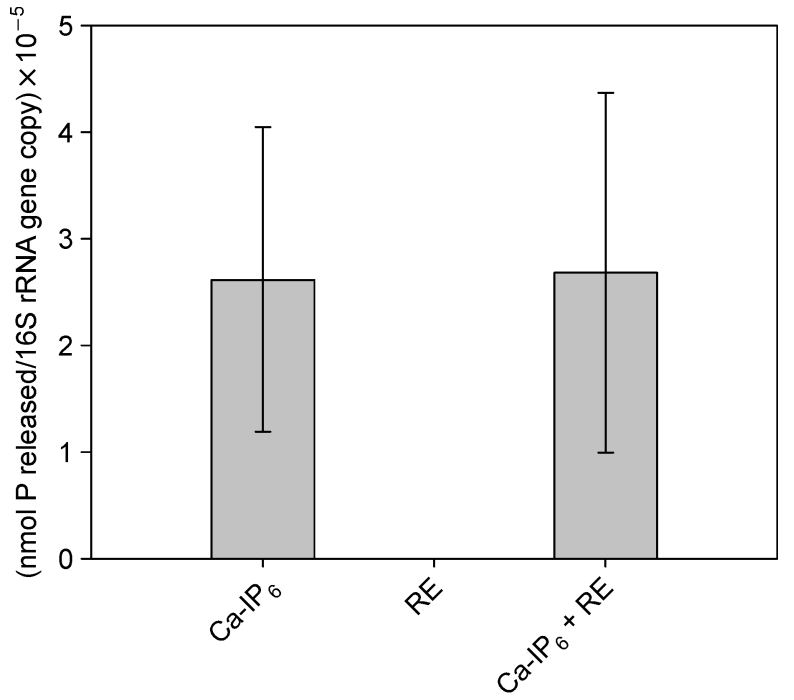

Fig. 2 Phytase assay on treatments showing released orthophosphate normalized to $16 \mathrm{~S}$ rRNA gene copy number. Values are calculated per GFF extraction using crude enzyme extracts of cell-associated materials in triplicate. The 16S rRNA copy numbers were determined as described in materials and methods. No activity was detected in the microcosm crude extract containing only root exudate (RE). Microcosms treatments were: calcium phytate alone $\left(\mathrm{Ca}-\mathrm{IP}_{6}\right)$, root-exudate alone $(\mathrm{RE})$, and calcium phytate combined with root-exudate $\left(\mathrm{Ca}-\mathrm{IP}_{6}+\right.$ $\mathrm{RE})$. Error bars are reported in SEM.

\subsection{Quantification of hotspot-associated bacteria and} quantification of functional genes involved in organic $\mathrm{P}$ cycling

To understand the population size in the bulk soil and between treatments, the total extractable 16S rRNA genes were quantified by qPCR. The bulk soil yielded $3.53 \times 10^{7} \pm 0.12$ $\times 10^{7}$ copies per gram of soil (Supplementary Figure S3). Different total number of bacteria were recruited from the various treatments (Kruskal-Wallis, $p=2.6 \times 10^{-7}$, Fig. 3).

The RE hotspot recruited more 16S rRNA gene copies than the hotspots containing Ca-phytate $\left(p<6.8 \times 10^{-5}\right)$. Addition of root exudate to the Ca-phytate embedded GFF (i.e., Ca-IP 6 $+\mathrm{RE}$ ) resulted in significantly more gene copies than hotspots containing only Ca-phytate (i.e., Ca-IP $\mathrm{P}_{6}, p=0.002$ ) alone, however, also significantly less than root exudate on its own ( $p$ $=6.8 \times 10^{-5}$ ).

Based on absolute gene copy numbers, phoD was most abundant followed by phoX, and then BPP (Fig. 4A). The total number of phosphatase gene copies (i.e., phoD + phoX + $B P P$ ) are highest in the $R E$ treatment (5230 copies \pm 1048 ) as compared to $\mathrm{Ca}-\mathrm{IP}_{6}+\mathrm{RE}(3676 \pm 211)$ and $\mathrm{Ca}-\mathrm{IP}_{6}(2233 \pm$ 535)(errors reported in SEM, Fig. 4A). The phoD, phoX, and 


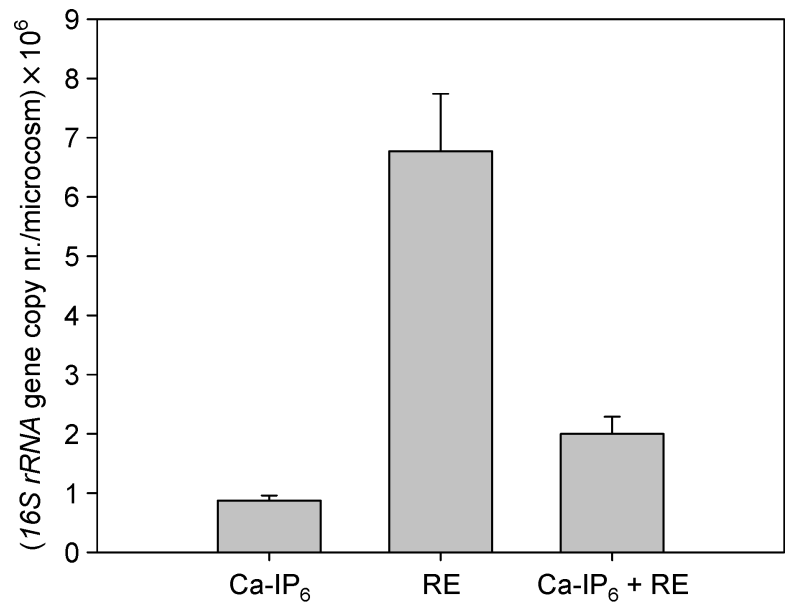

Fig. 3 16S rRNA gene copy numbers per microcosm. Microcosms treatments were: calcium phytate alone $\left(\mathrm{Ca}-\mathrm{IP}_{6}\right)$, rootexudate alone (RE), calcium phytate combined with root-exudate $\left(\mathrm{Ca}-\mathrm{IP}_{6}+\mathrm{RE}\right)$. The P-value shown is generated from the Kruskal-Wallis test and letters denote pairwise Mann-Whitney results. Error bars are shown in SEM.

$B P P$ genes were also measured per gram bulk soil (supplementary data, Figure S3), however, are not comparable to the absolute data from the microcosm, which is extracted from GFFs.

The relative abundance of $p h o X$, phoD, and $B P P$ were similarly calculated as gene copy per 16S rRNA gene copy number across all treatments as well as in bulk soil (Fig. 4B). Compared to bulk soil, specific enrichment of PhoX and PhoD was evident in the Ca-phytate hotspot, whereas gene abundance was decreased in the treatments with $\mathrm{RE}$ (Games-Howell and Tukey post-hoc respectively, $p<0.04$ ). No difference in relative abundance of BPP occurred across any hotspot treatment compared to bulk soil ( $p=0.24$, Welch's F test).

3.5 Catabolism fingerprinting of bacterial populations using BioLog®Eco plate

The hotspot treatment had a significant effect on community composition as assessed by the BioLog®Eco plates at alltime points tested ( $p<0.0001$, ANOSIM, Euclidean distance). However, the time point corresponding to half of the average well color development (AWCD) was 6 days (144 h) and was used for statistical analysis and data comparison. Pairwise ANOSIM comparisons indicated that the response between treatments differed with the following associated $p$ values; Ca$\mathrm{IP}_{6}$ and RE hotspots; $p<0.001, \mathrm{RE}$ and $\mathrm{Ca}-\mathrm{IP}_{6}+\mathrm{RE} ; p=$ 0.015 , and $\mathrm{Ca}-\mathrm{IP}_{6}$ and $\mathrm{Ca}-\mathrm{IP}_{6}+\mathrm{RE} ; p=0.051$ (Fig. 5). PCA visualization of the metabolic fingerprint indicated that the $\mathrm{Ca}$ $\mathrm{IP}_{6}+\mathrm{RE}$ treatment grouped between $\mathrm{Ca}-\mathrm{IP}_{6}$ and $\mathrm{RE}$.
3.6 Diversity comparison between microcosm treatments

Evaluation of a-diversity using a one-way ANOVA confirmed statistically significant effects of hotspot conditions by both Shannon and Chao-1 diversity measures $(p<0.0001)$. Posthoc analysis showed that all microcosm microbial communities had significantly lower $\alpha$-diversity as compared to the bulk soil microbial communities ( $p=0.0002$, Tukey, Fig. 6A and $\mathrm{B}$ ). In addition, the RE treatment showed significantly lower $\alpha$-diversity than the $\mathrm{Ca}-\mathrm{IP}_{6}$ treatment according to the Chao-1 index ( $p=0.029$, Tukey, Fig. 6A) and Shannon index $\left(p=0.026\right.$, Tukey, Fig. 6B), whereas the $\mathrm{Ca}-\mathrm{IP}_{6}+\mathrm{RE}$ hotspots revealed an intermediate level of $\alpha$-diversity.

Evaluation of the $\beta$-diversity showed significant differences between hotspot treatments as well as bulk soil, as visualized by PCA (Fig. 6C). The non-parametrical MANOVA analysis based on Bray-Curtis dissimilarity yielded a $P$-value of 0.0001 , with all pairwise comparisons being significantly different $(p<0.05)$ when tested at an OTU level. In the bulk soil, the most abundant phyla were Proteobacteria (43\%), Actinobacteria $(16 \%)$, Firmicutes (15\%) and Verrucomicrobia (12\%). Acidobacteria, Gemmatimonadetes, Chloroflexi, Planctomycetes, and Bacteroidetes each represented 1 to $4 \%$ of the obtained sequences, while the remaining phyla detected each represented less than $0.5 \%$ (Supplementary Table 2). Hotspot communities recruited from $53 \%$ to $71 \%$ OTUs matching the Actinobacteria phylum, followed by the Proteobacteria phylum (22 to $25 \%$ ). The phylum Firmicutes was represented highest in $\mathrm{Ca}-\mathrm{IP}_{6}+\mathrm{RE}(24 \%)$, followed by RE (12\%), and Ca-phytate $(4 \%)$. Aside from Bacteroidetes being highly represented in $\mathrm{RE}(7 \%)$, all other phyla were represented at levels less than $0.5 \%$ (Fig. 7A).

When looking specifically at the most abundant genera selected within each treatment, preferential selection of Bacillus and Variovorax was evident in the RE treatment, Streptomyces and Variovorax in the $\mathrm{Ca}_{-} \mathrm{IP}_{6}$ treatment, and Paenibacillus and Streptomyces in the $\mathrm{Ca}-\mathrm{IP}_{6}+\mathrm{RE}$ treatment, and relatively equal selection of Arthrobacter among all treatments (Fig. 7B).

All OTUs amounting to more than $0.5 \%$ total sample contribution were used in a Venn diagram to reveal shared and unique OTUs recruited by the distinct hotspot conditions (Fig. 7C). The Ca-IP 6 and $\mathrm{Ca}-\mathrm{IP}_{6}+\mathrm{RE}$ microcosms recruited 13 and 14 unique OTUs, respectively (i.e., OTUs that are not recruited in other treatments at an abundance over $0.5 \%$ ), while 10 OTUs were shared between the treatments (i.e., OTUs that were detected in both treatments). Of these 10 shared OTUs that were recruited by the $\mathrm{Ca}-\mathrm{IP}_{6}+\mathrm{RE}$ and the $\mathrm{Ca}-\mathrm{IP}_{6}$ hotspots, eight were classified within the Actinobacteria, the majority within the genus Streptomyces (Table 2). To exemplify the quantitative differences between sample treatments, the fold increase of $\mathrm{Ca}_{\mathrm{IP}} \mathrm{IP}_{6}$ OTUs relative to the REcontrol and the soil community is indicted (Table 2). 

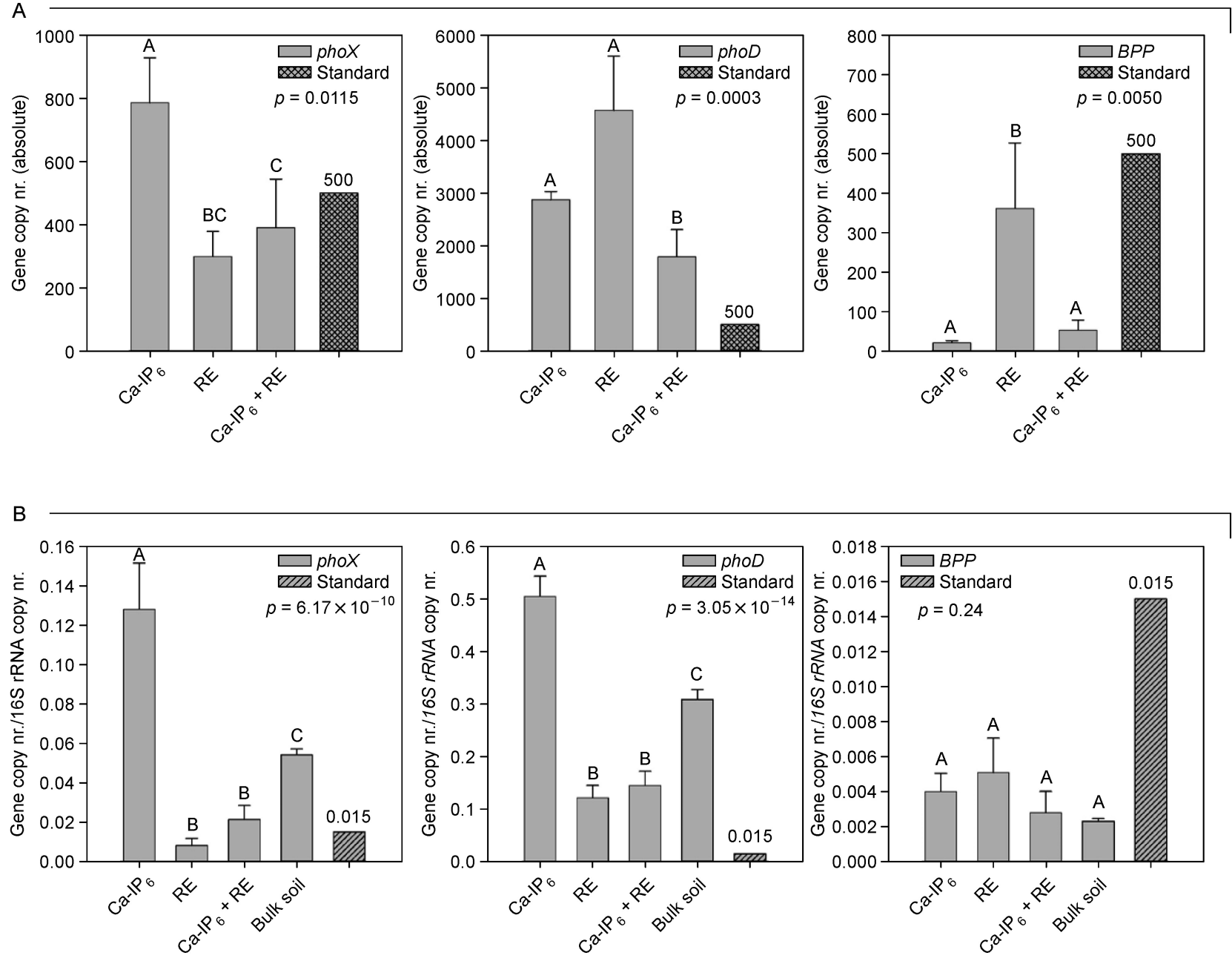

Fig. 4 Quantification of genes relating to organic phosphorus. (A) Absolute abundance of genes in each treatment. (B) Abundance of genes in each treatment normalized to $16 \mathrm{~S}$ rRNA gene copy number. Microcosms treatments were: calcium phytate alone $($ Ca-IP $)$, root-exudate alone $(\mathrm{RE})$, calcium phytate combined with root-exudate $\left(\mathrm{Ca}-\mathrm{IP}_{6}+\mathrm{RE}\right)$. phoX $=$ alkaline phosphatase, $p h o D=$ alkaline phosphatase, $B P P=$ beta propeller phytase. Error is shown in SEM. Statistical comparisons were done using Kruskal-Wallis with Mann-Whitney post-hoc pairwise evaluations for the absolute gene numbers, whereas Fisher and Welches ANOVA with appropriate post-hoc pairwise evaluations were used for the relative abundance comparisons. Shaded standard bars are included to assist in drawing comparisons.

\section{Discussion}

In the present study, the baiting approach was developed and used to reveal more general knowledge on the ecology of soil microbial communities with potential for organic $\mathrm{P}$ mineralization in soil. With the long-term perspective of isolating biofertilizer strains for use in agriculture with improved ability to function in natural soil settings, parameters for the microcosm were thoughtfully selected. The soil used for the microcosm setup contained significant amounts of phytate but low available $P$, previously shown to be preferred conditions for phytase action (Ramírez and Kloepper, 2010). An artificial root exudate was selected to simulate rhizosphere conditions and provide an extra carbon (energy) source beside the Caphytate. A $10 \mu \mathrm{m}$ mesh net was wrapped around the microcosm to create distance between the bait substrate and soil to select for mobile bacteria and keep the filter free from debris. Finally, Ca-phytate was chosen as a relevant "bait" substrate since it is a predicted form of organic $P$ in neutral to alkaline agricultural soils (Jackman, 1951; von Wandruszka, 2006).

\subsection{Population functionality toward calcium phytate}

To test if the recruited populations showed any activity toward the bait substrate, breakdown of Ca-phytate was indirectly assessed by HPLC quantification of remaining myo-inositol 


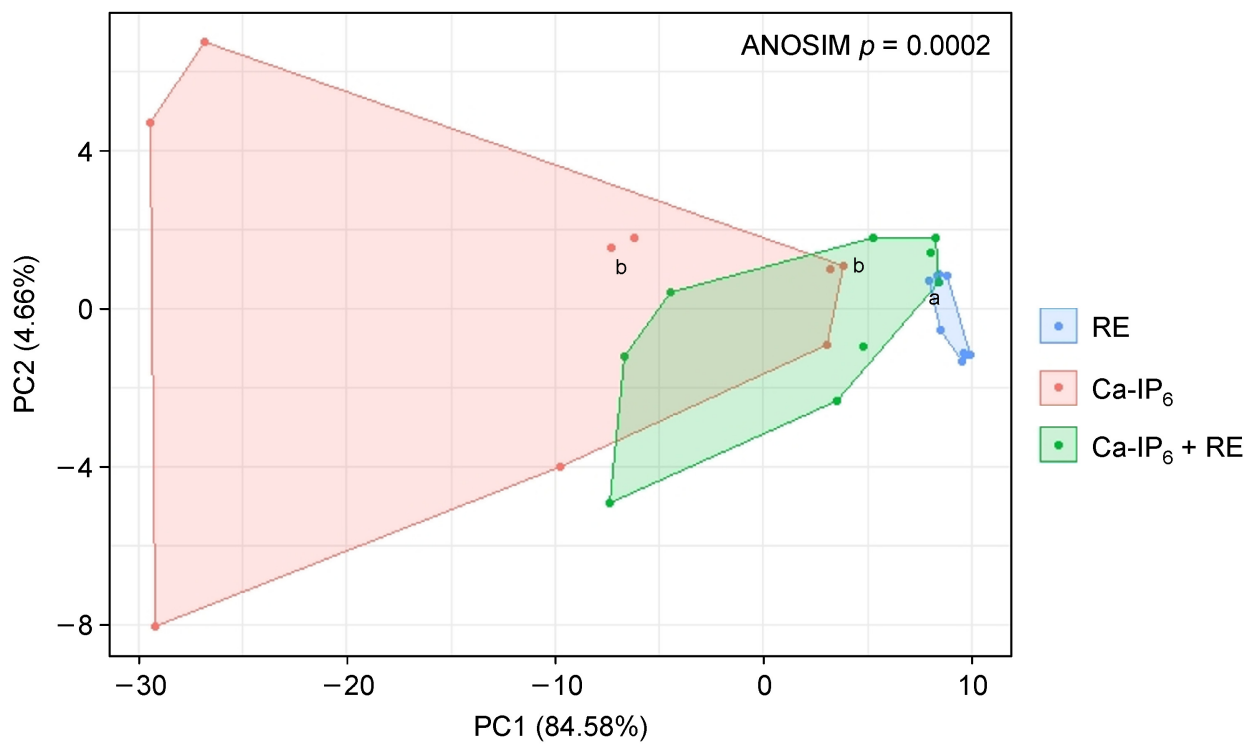

Fig. 5 BioLog ECO plate data represented in a principle components analysis (PCA). The shaded areas represent convex hulls enclosing assigned treatment points in the Euclidian plane. Microcosms treatments were: calcium phytate alone $\left(\mathrm{Ca}-\mathrm{IP}_{6}\right)$, root-exudate alone $(\mathrm{RE})$, and calcium phytate combined with root-exudate $\left(\mathrm{Ca}-\mathrm{IP}_{6}+\mathrm{RE}\right)$. A blank microcosm control was not included as insufficient biomass was obtained for the assay.

phytate post-incubation and released orthophosphate was quantified from each treatments' crude enzyme extract in a modified phytase assay. An overwhelming majority of published phytase assays are buffered at $\mathrm{pH} 5$ and utilize a soluble Na-phytate, however, the modified phytase assay used here was buffered at $\mathrm{pH} 7.2$ and utilized a precipitated Ca-phytate (Engelen et al., 1994; Tang et al., 2006). Using precipitated Ca-phytate, we aim to better mimic the bioavailability challenges of persistent insoluble Ca-phytate salts in alkaline soils. Using a precipitated substrate means that the enzymes cannot not act with maximum velocity (MichealisMenten kinetics), since the concentration of $\mathrm{IP}_{6}$ available to the enzymes is quite low in the reaction mixture. However, despite the added substrate availability challenge, orthophosphate release from Ca-phytate was detected from both hotspots employing $\mathrm{Ca}$-phytate as a bait substrate (i.e., Ca$\mathrm{IP}_{6}$ and $\mathrm{Ca}-\mathrm{IP}_{6}+\mathrm{RE}$ treatments). We consider this an encouraging indication that the population recruited by these hotspots was functionally enriched. Furthermore, in this assay we forfeit extracellular enzyme fractions, as only the fractions physically remaining on the GFF can be removed from soil (i.e., cell-associated extracellular enzymes as well as intracellular enzymes). Therefore, while the values obtained from the phytase assay were low in comparison to other published reports (Richardson and Hadobas, 1997; Giles et al., 2018), the above-listed limitations of the modified phytase assay would substantiate this. We consider the limitations of the modified assay a reasonable trade-off for a more representative insight to soil biochemistry surrounding organic $P$ cycling.

While the phytase assay showed orthophosphate release in both $\mathrm{Ca}-\mathrm{IP}_{6}$-containing hotspots, the HPLC assay could only detect clearance of myo-inositol phosphate $\left(\mathrm{IP}_{6}\right)$ in the Ca-IP $6+R E$ hotspot (Fig. 2, Table 1). This is likely because the $\mathrm{Ca}-\mathrm{IP}_{6}+\mathrm{RE}$ sample recruited more bacterial numbers than the $\mathrm{Ca}_{\mathrm{IP}} \mathrm{P}_{6}$ alone, as estimated by $16 \mathrm{~S}$ rRNA gene quantities (Fig. 3), which has the potential to realize greater substrate cleavage and consumption. This is supported by the reported phytase assay values prior to normalization $(23.6 \pm$ $13.2 \mathrm{nmol}$ and $54.4 \pm 36.5 \mathrm{nmol}$ of $\mathrm{P}$ from the $\mathrm{Ca}-\mathrm{IP}_{6}$ and the Ca-IP 6 + RE hotspots respectively). However, as the substrate availability to the enzyme is assumed to be the same in both samples, it is plausible that the populations from the two hotspots produced comparable amounts of phytate degrading enzymes per bacterium as seen in Fig. 2. Finally, while the final product of phytases involve a lower order inositol phosphate ( $\left.\mathrm{IP}_{5}-\mathrm{IP}_{1}\right)$ (Oh et al., 2001; Shin et al., 2001; Shim and Oh, 2012), we detect no lower myo-inositol phosphates in our post-incubation HPLC results. A low $\mathrm{IP}_{6}$ availability will consequently result in small amounts of lower order myo-inositol phosphates which are prone to further dephosphorylation, as they are more easily accessible to the phosphatases present in the general population. Therefore, we hypothesize that the total functional capacity of the soil microbiota is able to clear the lower order products quickly, resulting in concentrations of lower order myo-inositol phosphates below the detection limit of the HPLC system used. Overall, we take the combination of released $\mathrm{Pi}$ from Ca-phytate in the phytase assay and clearance of myoinositol phosphate in the HPLC assay as an indication that the population from $\mathrm{Ca}-\mathrm{IP}_{6}$-containing hotspots can degrade $\mathrm{Ca}$ phytate at $\mathrm{pH} 7.2$, albeit, slowly. The observations therefore suggest dephosphorylation of only the soluble fraction Ca- 

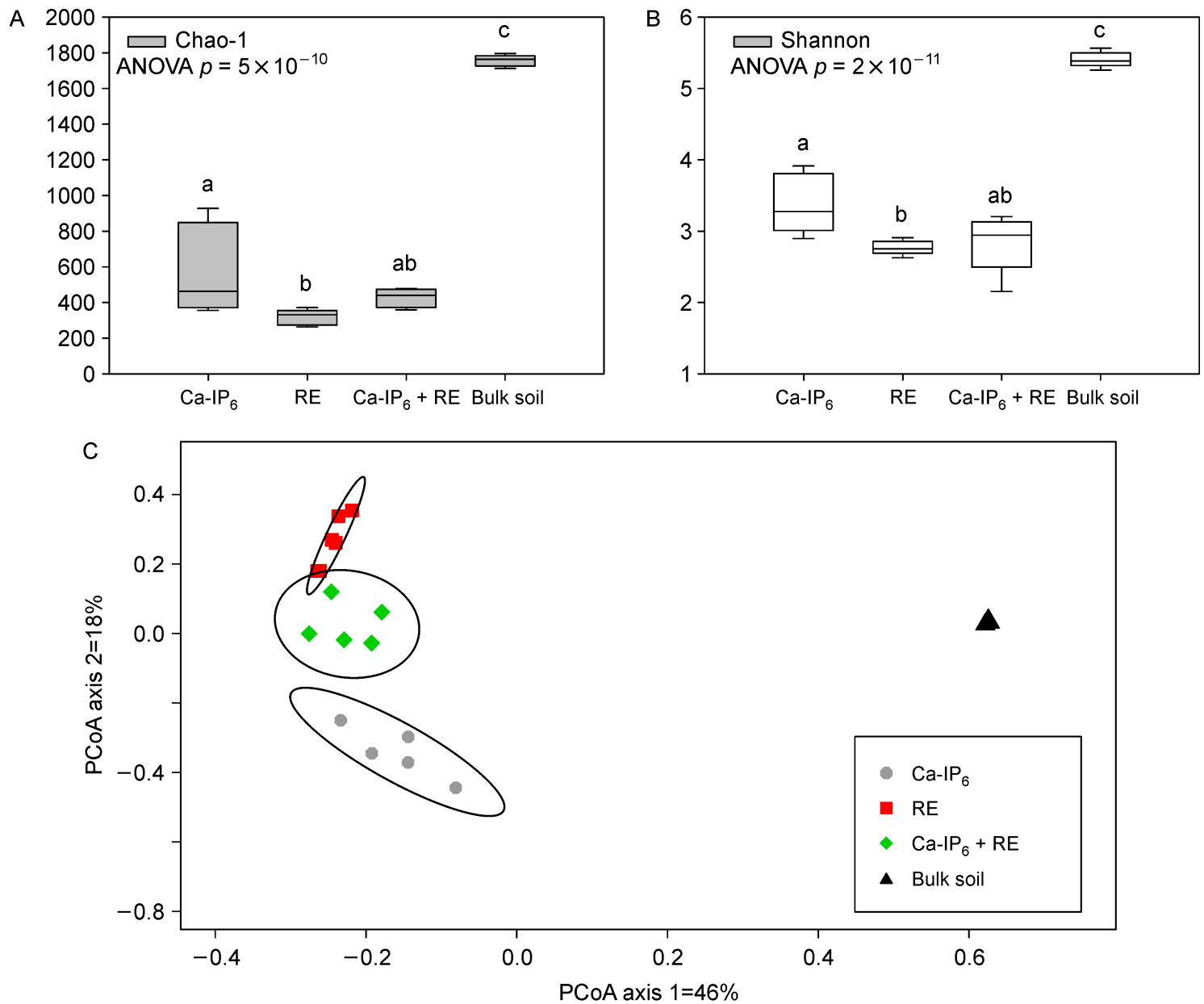

Fig. 6 Diversity analysis of microcosm microbial communities. (A) Shannon $\alpha$-diversity and (B) Chao-1 $\alpha$-diversity between microcosm treatments with differences (indicated by different letters) determined using a two-tailed $t$-test. $C$. $\beta$-diversity across treatment hotspots shown by Principal coordinate analysis (PCOA) of OTUs originating from the microcosm treatments and bulk soil. Treatments were: calcium phytate alone $\left(\mathrm{Ca}-\mathrm{IP}_{6}\right)$, root-exudate alone $(\mathrm{RE})$, calcium phytate combined with root-exudate $\left(\mathrm{Ca}-\mathrm{IP} \mathrm{P}_{6}+\mathrm{RE}\right)$, and bulk soil. A Bray-Curtis dissimilarity matrix was applied for ordination of the normalized (relative abundance) and rarefied data. Ellipses drawn represent a standard deviation of the data based on $95 \%$ confidence interval.

phytate present in an equilibrium with insoluble Ca-phytate, which appears unavailable to the enzyme.

\subsection{Quantified 16S rRNA and phosphatase gene abundance}

The estimated bacterial abundance in each hotspot and bulk soil was measured via qPCR of the 16S rRNA gene. Results from the bulk soil are in agreement with other studies quantifying 16S rRNA in nutrient-deficient soils (Keshri et al., 2015), and as expected, significantly different bacterial numbers were recruited by the various hotspots (Fig. 3). Total 16S rRNA numbers do not take bacterial turnover through death and degradation into account, nor predation of bacteria by other microorganisms (Rousk and Bååth, 2011). Furthermore, our data only estimates microorganisms from the bacterial kingdom containing the $16 \mathrm{~S}$ rRNA gene, but especially in the sample supplied with both $\mathrm{C}$ and $\mathrm{P}\left(\mathrm{Ca}-\mathrm{IP}_{6}\right.$ $+\mathrm{RE}$ ), micro-eukaryotes that can pass through the $10 \mu \mathrm{m}$ mesh (fungi and protozoa) are more likely also to be at play, as they are attracted to the resulting dense and diverse bacterial population (Rosenberg et al., 2009; Jousset, 2012; Otto et al., 2017). Therefore, predation and higher numbers of eukaryotes may be the reason that lower 16S rRNA numbers were found in the $\mathrm{Ca}-\mathrm{IP}_{6}+\mathrm{RE}$ sample. The lowest number of bacteria were recruited to the Ca-phyate only treatment $(\mathrm{Ca}-$ $\mathrm{IP}_{6}$ ), which would suggest that this sample presents both challenging forms of $P$ and $C$. The soil used in the study contained phytate and other forms of complex $P$, explaining the results seen in the root exudate (RE) control microcosm. However, the high total number of absolute gene copies of phosphatase (i.e., phoD + phoX + BPP, Fig. 4A) in the RE treatment can be used to confirm that the P-deficient soil used had pre-selected P-degrading functionality, since high potential to liberate $P$ was observed when $C$ was provided.

The organic P-cycling genes tested included phoD and phoX encoding alkaline phosphatases, and BPP, specific to 

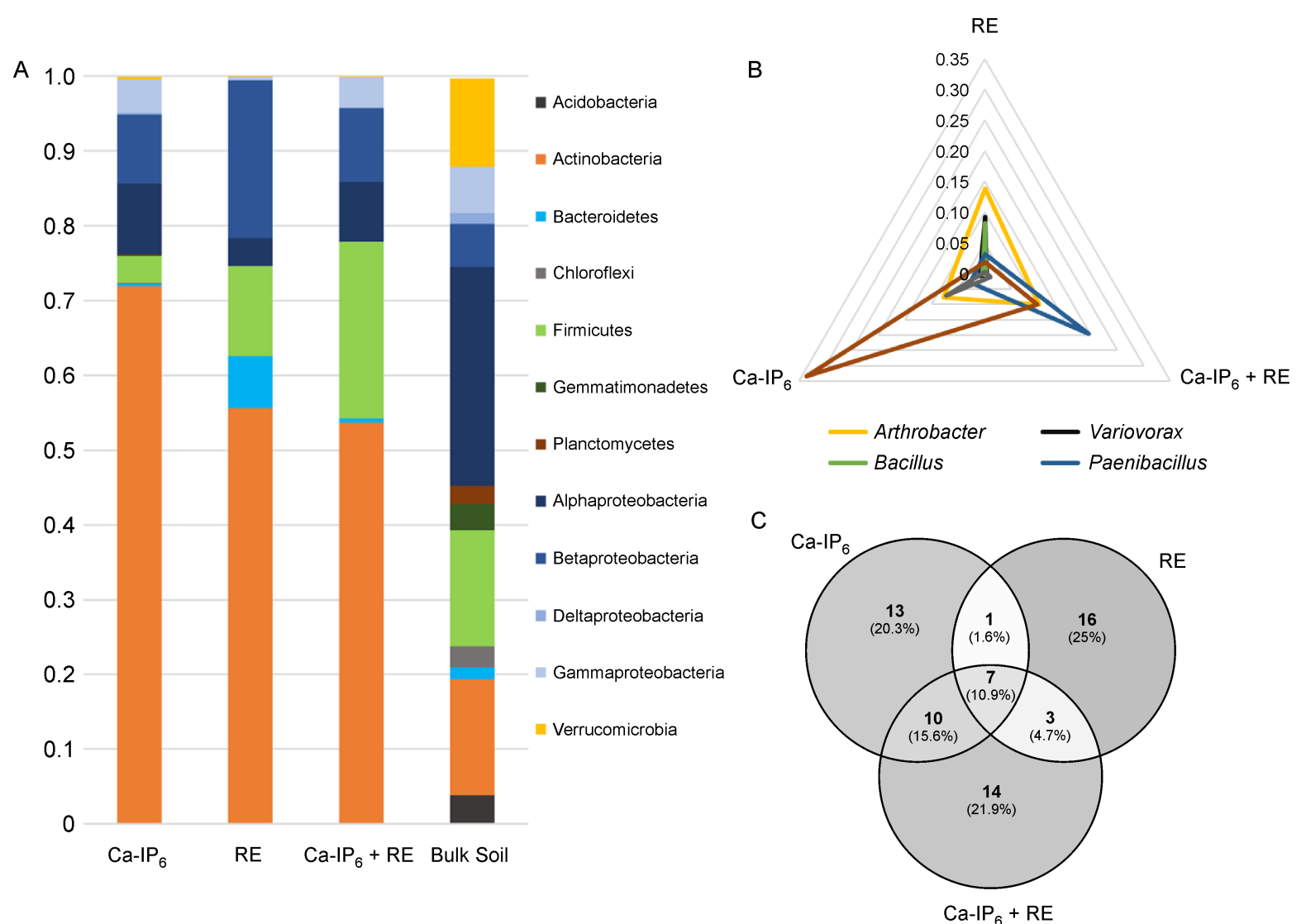

Fig. 7 Community composition based on $16 \mathrm{~S}$ sequence analysis and OTU similarity across microcosm hotspot treatments. (A) Stacked bar chart displaying the treatment profiles at a phyla level. OTUs were identified at a $97 \%$ similarity level with families representing more than $0.5 \%$ abundance being shown. (B) Radar plot displaying the top three most abundant assigned genera based on OTUs in each microcosm treatment. (C) Venn diagram showing relevant shared and individual OTUs (and total percentage) per hotspot treatment. Only OTUs representing greater than $0.5 \%$ abundance were chosen for comparisons. Microcosms treatments were: calcium phytate alone $\left(\right.$ Ca-IP $\left.{ }_{6}\right)$, rootexudate alone $(\mathrm{RE})$, calcium phytate combined with root-exudate $\left(\mathrm{Ca}-\mathrm{IP}_{6}+\mathrm{RE}\right)$, and bulk soil.

the hydrolysis of Ca-phytate. phoD is shown to exhibit phosphodiesterase ability and phoX is shown to act on phosphate monoesters (Roy et al., 1982; Gomez and Ingram, 1995). Therefore, the presence of these genes represents an opportunity to cleave orthophosphate from lower order myoinositol phosphates. We hypothesized that the presence of organic $\mathrm{P}$ (Ca-phytate) would result in a recruitment and activity of microorganisms carrying these organic $P$ degradation-related genes as compared to environments without organic C present (RE-microcosms). This response was, however, only seen in the $\mathrm{Ca}-\mathrm{IP}_{6}$ hotspot, and only in phoX and $p h o D$. Since both phoX and $p h o D$ abundance have been shown to respond to organic $\mathrm{P}$ and $\mathrm{C}$, and the phoD abundance showed a particularly strong correlation to soil organic C (Ragot et al., 2017), these results are likely explained by the lack of easily accessible $C$ and $P$ on the Ca-IP 6 microcosm. Looking specifically at the Ca-IP 6 and the Ca-IP $6+R E$, the latter is supplied with a more diverse array of organic $\mathrm{C}$ and recruits sufficient microbial biomass to release orthophosphate from $\mathrm{IP}_{6}$ as measured in the non-normalized phytase assay (as reported) and the degradation of $\mathrm{Ca}$ phytate as observed by HPLC. When nutrients become available via successful extracellular phosphatase activity, scavenger bacteria (i.e. those without alkaline phosphatase genes in their genome) will also benefit and grow. This would result in a diluted population carrying our genes of interest. Thus, in the CalP $_{6}+\mathrm{RE}$ hotspot where more total $P$ is released, a lower relative gene copy per 16S rRNA gene would be expected as shown in $4 \mathrm{~B}$. While the relative abundance of the BPP being low in comparison to phoD and phoX has previously been shown (Neal et al., 2017; Neal and Glendining, 2019), we did not see any difference in relative BPP abundance when compared between treatments (Fig. 4B). However, the detected phytase/phosphatase enzyme activity as well as the detected loss of $\mathrm{IP}_{6}$ in our HPLC assay support that alkaline phytase enzymes are active in our Ca-phytate-containing hotspots (Table 1, Fig. 2). This challenges the view that BPP enzymes are main contributors to $\mathrm{Ca}-\mathrm{IP} \mathrm{P}_{6}$ degradation in alkaline soil systems (Jorquera et al., 2013). There are, however, multiple explanations for this. First, the expression and downstream action of the BPP enzyme varies between treatments, which is supported by the BPP gene quantification showing equal relative gene copies in all populations (Fig. 4B), while the phytase assay detected 
Table 2 High abundance OTUs shared between Ca-phytate and Ca-phytate + RE treatments.

\begin{tabular}{|c|c|c|c|c|}
\hline (Phyla) genus species & $\begin{array}{l}\% \text { abundance } \\
\text { in } \mathrm{Ca}-\mathrm{IP}_{6}\end{array}$ & $\begin{array}{c}\% \text { abundance in } \\
\mathrm{Ca}^{-\mathrm{IP}_{6}}+\mathrm{RE}\end{array}$ & $\begin{array}{c}\% \text { abundance in RE } \\
\text { (fold change } \\
\text { of } \mathrm{Ca}-\mathrm{IP}_{6} \text { to } \mathrm{RE} \text { ) }\end{array}$ & $\begin{array}{c}\% \text { abundance } \\
\text { in bulk soil } \\
\text { (fold change of } \mathrm{Ca}-\mathrm{IP}_{6} \\
\text { to bulk soil) }\end{array}$ \\
\hline (Actinobacteria), Streptomyces sp. (OTU485) & 3.3 & 1.1 & $1.2 \times 10^{-3}(26)$ & $6.1 \times 10^{-4}(53)$ \\
\hline (Actinobacteria), Streptomyces sp. (OTU1106) & 3.1 & 1.6 & $3.1 \times 10^{-3}(9)$ & $1.6 \times 10^{-4}(196)$ \\
\hline (Actinobacteria), Streptomyces sp. (OTU299) & 2.9 & 1.7 & $1.7 \times 10^{-3}(16)$ & $2.5 \times 10^{-4}(119)$ \\
\hline $\begin{array}{l}\text { (Actinobacteria), Streptomyces atratus } \\
\text { (OTU1426) }\end{array}$ & 2.3 & 0.6 & $1.8 \times 10^{-4}(126)$ & $4.7 \times 10^{-5}(488)$ \\
\hline (Proteobacteria), Microvirga" sp. (OTU205) & 2.2 & 0.6 & $1.3 \times 10^{-3}(16)$ & $6.6 \times 10^{-4}(32)$ \\
\hline $\begin{array}{l}\text { (Actinobacteria), Promicromonospora sp. } \\
\text { (OTU1755) }\end{array}$ & 2.0 & 0.8 & $1.3 \times 10^{-3}(14)$ & 0.0 (\#\#) \\
\hline (Actinobacteria), Streptomyces sp. (OTU1192) & 1.0 & 0.5 & $1.5 \times 10^{-3}(6)$ & $6.9 \times 10^{-6}(1461)$ \\
\hline (Actinobacteria), Nocardia sp. (OTU1751) & 0.9 & 0.6 & $2.8 \times 10^{-3}(2)$ & $2.8 \times 10^{-5}(321)$ \\
\hline (Actinobacteria), Streptacidiphilus sp. (OTU172) & 0.7 & 0.9 & $1.5 \times 10^{-3}(4)$ & $1.3 \times 10^{-5}(582)$ \\
\hline (Firmicutes), Paenibacillus sp. (OTU1577) & 0.8 & 1.0 & $8.7 \times 10^{-4}(8)$ & $1.3 \times 10^{-5}(631)$ \\
\hline
\end{tabular}

Data are derived from the Venn diagram (Fig. 7C) with OTUs having an abundance of higher than $0.5 \%$ in Ca-IP6 and Ca-IP6 + RE samples and being absent or lower than $0.5 \%$ abundance in RE and bulk soil samples (note that OTUs that are completely absent in RE or bulk soil cannot yield a fold change value). \# Microvirga was previously classified as Balneimonas, "\# was absent from bulk soil.

orthophosphate-release only in $\mathrm{Ca}-\mathrm{IP}_{6}$ and $\mathrm{Ca}-\mathrm{IP}_{6}+\mathrm{RE}$ hotspot populations (Fig. 2). Second, a $\mathrm{C}$ limitation drives the population evolution, necessitating only small amounts of the BPP enzyme to cleave the first phosphate off the inositol ring and render lower order myo-inositol phosphates theoretically available to other phosphatases (i.e., $P h o D$ and $P h o X$ ) and myo-inositol dehydrogenases. Soil bacteria are able to utilize myo-inositol as a C source (Yoshida et al., 1997; Fry et al., 2001; Yebra et al., 2007), therefore, it is not unreasonable to assume that the recruited populations would utilize both the $C$ and $P$ from Ca-phytate. This would further support the lack of lower order myo-inositol phosphate products observed in our HPLC assay and suggests that the soils used are not only limited in bio-available $\mathrm{P}$ but also in bio-available $\mathrm{C}$ (Demoling et al., 2007). Third, the BPP primers employed do not cover enough sequence variability to capture the full BPP profile. While there have been various attempts to develop degenerate BPP primers (Huang et al., 2009, Jorquera et al., 2013, Lim et al., 2007); a broad consensus remains that the currently-available primers are unable to capture the BPP profile believed to be present based on in-vitro evidence (Sanguin et al., 2016). Finally, there is the possibility that another novel or overlooked phytase acts in alkaline-buffered systems. Soil microorganisms in healthy, fertile soils provide a degree of functional redundancy (Jurburg and Salles, 2015; Jia and Whalen, 2020) however, the BPP is the only known microbial phytase to act under neutral or alkaline conditions. It is therefore not unreasonable to suggest that other enzymes are able to perform this task. Furthermore, as there is limited information available on the substrate specificity of the PhoX and $P h o D$ in relation to phytate, and both have been shown to necessitate $\mathrm{Ca}^{2+}$ ions and function under alkaline conditions (Roy et al., 1982; Gomez and Ingram, 1995). Therefore, we speculate that these enzymes play a larger role in phytate degradation than previously shown. Further studies need to be undertaken to reveal the functional role of $P h o X$ and $P h o D$ in cycling of phytate in the soil environment.

\subsection{General population studies}

To investigate the broad community differences between treatment populations in a time-sensitive manner, the catabolic profiles of the hotspot communities were subjected to BioLog®Eco plates. Here, a wide range of soil-specific substrates were monitored and provided initial insights into population differences, showing that the RE community was considerably different from the Ca-phytate-harboring communities $\left(\mathrm{Ca}-\mathrm{IP}_{6}\right.$ and $\left.\mathrm{Ca}-\mathrm{IP}_{6}+\mathrm{RE}\right)$, while the Ca-phytateharboring communities in themselves showed a less distinct difference (Fig. 5). These differences in community composition were further verified by $16 \mathrm{~S}$ rRNA amplicon sequencing, where designation of OTU's and SIMPER analysis provided deeper resolution. As such we showed that the hotspot bacterial communities were significantly different and less 
diverse than the soil bacterial community. A decrease in microbial community diversity is in agreement with previous studies on other hotspot environments, for example roots (Yousuf et al., 2012; Aislabie and Deslippe, 2013) and fungal hyphae (Ghodsalavi et al., 2017; Hao et al., 2020) as compared to soil communities. As per SIMPER analysis, these differences were largely driven by the presence of Bacteriodetes at higher levels in RE hotspots receiving only root exudates, a high relative abundance of Firmicutes in Ca$\mathrm{IP}_{6}+\mathrm{RE}$ hotspots, and relatively increased abundance of Actinobacteria in $\mathrm{Ca}-\mathrm{IP}_{6}$ hotspots receiving only $\mathrm{Ca}$-phytate (Fig. 7A). Abundance of Actinobacteria in all hotspots of more than $50 \%$ is in concordance with this phylum being dominant in bulk soils with limited organic matter and especially in soils abundant in phytate availability (Bell et al., 2014; Neal et al., 2017). In the present study the findings of Bacteroidetes in RE hotspots, is supported by Bacteroidetes being classified as copiotrophic groups commonly detected in C-enriched environments such as the rhizosphere (Yousuf et al., 2012; Aislabie and Deslippe, 2013). Likewise, our findings of Firmicutes in the $\mathrm{Ca}-\mathrm{IP}_{6}+\mathrm{RE}$ hotspots fit with previous studies showing that the phyla, and specifically the genus Bacillus, responds quickly to additions of organic material (Fierer et al., 2007). Finally, our Ca-IP 6 hotspot findings further compliment the findings by Sanguin et al. (2016) who employed a culture-independent 16S rRNA gene-DGGE study of the grass rhizosphere, and showed predominance of Proteobacteria and Actinobacteria in Na-phytate treated alkaline soils.

A majority of the phytate-hydrolyzing soil strains recognized presently have been isolated and/or identified using culturedependent methods. These methods have largely yielded fast growing Pseudomonas and Bacillus strains from bulk soils (Richardson and Hadobas, 1997; Idriss et al., 2002), and Pseudomonas, Enterobacter, Pantoea, and Burkholderia spp. from plant rhizospheres (Unno et al., 2005; Jorquera et al., 2008). When considering our OTU assignments, a specific increase of Streptomyces within the Actinobacteria phyla was evident in the $\mathrm{Ca}^{-\mathrm{IP}_{6}}$ treatment (Fig. 7A). Furthermore, a majority of the OTUs recognized as shared between $\mathrm{Ca}-\mathrm{IP}_{6}$ and $\mathrm{Ca}-\mathrm{IP}_{6}+\mathrm{RE}$ microcosms were Streptomyces (Table 2), indicating a genus of potential interest in the context of organic $P$ cycling. A recent cloning and confirmation of a BPP in Streptomyces sp. UD42 (Boukhris et al., 2016) and a study of bacterioplankton (Valdespino-Castillo et al., 2017), as well as a search of the published full genome of $S$. atratus strain OK807 (UniProt), confirms that some Streptomyces contain phytases and phosphatases (including BPP and phoD) and emphasizes the potential of Streptomyces in phytate mineralization in an agricultural setting. Aside from putative phytase genes detected in selected Streptomyces species (GhorbaniNasrabadi et al., 2012), many of the OTU assignments we report (Table 2) have no literature supporting the presence of a known phytase enzyme, yet these OTU's were shown to be abundant and specific in hotspots specifically containing $\mathrm{Ca}$ - phytate. Therefore, our findings highlights the current lack of knowledge surrounding the identity of phytate degraders in soil systems.

\section{Concluding statements}

The microcosm system developed in this paper was designed with the understanding that our ability to comprehensively dissect soil's complex mechanisms and interactions remains limited. The intended use of this microcosm is to by-pass this lack of knowledge yet use the highly evolved soil systems' inherent potential. This microcosm represents a breakthrough concept that could aid soil microbial ecology research in relation to multiple soil substrates. Using this microcosm approach, we were able to show specific recruitment of taxonomically and functionally distinct bacterial populations attracted to organic phosphorus $\left(\mathrm{Ca}-\mathrm{IP}_{6}\right)$. Our results propose putting emphasis on Actinobacteria, and in particular, the genus Streptomyces when screening and testing for new biofertilizers to address recalcitrant soil organic $P$. We further conclude that our microcosm design presents a new option for isolating microorganisms with potential to be effective in solum and brings us a step closer to being able to isolate targeted and competitive microorganisms with specific functional traits for agricultural use.

\section{Acknowledgments}

A special thank you to Dorthe Ganzhorn for the technical support in the laboratory. This study was funded by innovation foundation Denmark, grant number 1308-00016B under the project Microbial biofertilizers for enhanced Crop availability of $P$ pools in soil and waste (MiCroP).

\section{Electronic supplementary material}

Supplementary material is available in the online version of this article at https://doi.org/10.1007/s42832-021-0089-z and is accessible for authorized users.

\section{References}

Aislabie, J., Deslippe, J.R., 2013. Soil microbes and their contribution to soil services. Ecosystem Services in New Zealand: Conditions and Trends, 143-161.

Bell, C., Carrillo, Y., Boot, C.M., Rocca, J.D., Pendall, E., Wallenstein, M.D., 2014. Rhizosphere stoichiometry: are C:N:P ratios of plants, soils, and enzymes conserved at the plant species-level? New Phytologist 201, 505-517.

Bhardwaj, D., Ansari, M.W., Sahoo, R.K., Tuteja, N., 2014. Biofertilizers function as key player in sustainable agriculture by improving soil fertility, plant tolerance and crop productivity. Microbial Cell Factories 13, 66. 
Boukhris, I., Farhat-Khemakhem, A., Bouchaala, K., Virolle, M.J., Chouayekh, H., 2016. Cloning and characterization of the first actinomycete $\beta$-propeller phytase from Streptomyces sp. US42. Journal of Basic Microbiology 56, 1080-1089.

Clarke, K.R., 1993. Non-parametric multivariate analyses of changes in community structure. Australian Journal of Ecology 18, 117-143.

Cordell, D., Rosemarin, A., Schröder, J.J., Smit, A.L., 2011. Towards global phosphorus security: a systems framework for phosphorus recovery and reuse options. Chemosphere 84, 747-758.

Cordell, D., White, S., 2011. Peak phosphorus: Clarifying the key issues of a vigorous debate about long-term phosphorus security. Sustainability 3, 2027-2049.

Cuong, N.D., Nicolaisen, M.H., Sørensen, J., Olsson, S., 2011. Hyphae-Colonizing Burkholderia sp.-A new source of biological control agents against sheath blight disease (Rhizoctonia solani $A G 1-I A)$ in rice. Plant Microbe Interactions 62, 425-434.

D’Angelo, E., Crutchfield, J., Vandiviere, M., 2001. Rapid, sensitive, microscale determination of phosphate in water and soil. Journal of Environmental Quality 30, 2206-2209.

de Menezes, A.B., Richardson, A.E., Thrall, P.H., 2017. Linking fungal-bacterial co-occurrences to soil ecosystem function. Current Opinion in Microbiology 37, 135-141.

DeSantis, T.Z., Hugenholtz, P., Larsen, N., Rojas, M., Brodie, E.L., Keller, K., Huber, T., Dalevi, D., Hu, P., Andersen, G.L., 2006. Greengenes, a chimera-checked 16S rRNA gene database and workbench compatible with ARB. Applied and Environmental Microbiology 72, 5069-5072.

Demoling, F., Figueroa, D., Bååth, E., 2007. Comparison of factors limiting bacterial growth in different soils. Soil Biology \& Biochemistry 39, 2485-2495.

Doolette, A.L., Smernik, R.J., McLaren, T.I., 2017. The composition of organic phosphorus in soils of the Snowy Mountains region of south-eastern Australia. Soil Research (Collingwood, Vic.) 55, 10 18.

Engelen, A.J., van der Heeft, F.C., Randsdorp, P.H.G., Smit, E.L., the Simple and Rapid Determination of Phytase Activity, 1994. Simple and rapid determination of phytase activity. Journal of AOAC International 77, 760-764.

Fierer, N., Bradford, M.A., Jackson, R.B., 2007. Toward an ecological classification of soil bacteria. Ecology 88, 1354-1364.

Fry, J., Wood, M., Poole, P.S., 2001. Investigation of myo-inositol catabolism in Rhizobium leguminosarum bv. viciae and its effect on nodulation competitiveness. Molecular Plant-Microbe Interactions 14, 1016-1025.

George, T.S., Hinsinger, P., Turner, B.L., 2016. Phosphorus in soils and plants-facing phosphorus scarcity. Plant and Soil 401, 1-6.

Gerke, J., 2015. Phytate (inositol hexakisphosphate) in soil and phosphate acquisition from inositol phosphates by higher plants. A review. Plants (Basel, Switzerland) 4, 253-266.

Ghodsalavi, B., Svenningsen, N.B., Hao, X., Olsson, S., Nicolaisen, M.H., Al-Soud, W.A., Sørensen, S.J., Nybroe, O., 2017. A novel baiting microcosm approach used to identify the bacterial community associated with Penicillium bilaii hyphae in soil. PLoS One 12, e0187116.

Ghorbani-Nasrabadi, R., Greiner, R., Alikhani, H.A., Hamedi, J., 2012. Identification and determination of extracellular phytate-degrading activity in actinomycetes. World Journal of Microbiology \& Biotechnology 28, 2601-2608.

Giles, C.D., Richardson, A.E., Cade-Menun, B.J., Mezeli, M.M., Brown, L.K., Menezes-Blackburn, D., Darch, T., Blackwell, M.S., Shand, C.A., Stutter, M.I., Wendler, R., Cooper, P., Lumsdon, D.G., Wearing, C., Zhang, H., Haygarth, P.M., George, T.S., 2018. Phosphorus acquisition by citrate- and phytase-exuding Nicotiana tabacum plant mixtures depends on soil phosphorus availability and root intermingling. Physiologia Plantarum 163, 356-371.

Gomez, P.F., Ingram, L.O., 1995. Cloning, sequencing and characterization of the alkaline phosphatase gene ( $p h o D)$ from Zymomonas mobilis. FEMS Microbiology Letters 125, 237-245.

Hao, X., Zhu, Y.G., Nybroe, O., Nicolaisen, M.H., 2020. The composition and phosphorus cycling potential of bacterial communities associated with hyphae of Penicillium in soil are strongly affected by soil origin. Frontiers in Microbiology 10, 2951.

Heinonen, J.K., Lahti, R.J., 1981. A new and convenient colorimetric determination of inorganic orthophosphate and its application to the assay of inorganic pyrophosphatase. Analytical Biochemistry 113, 313-317.

Hoff-Jøorgensen, E., 1944. Investigations on the solubility of calcium phytate. Kobenhavn: I kommission hos E. Munksgaard. 27 p.

Huang, H., Shi, P., Wang, Y., Luo, H., Shao, N., Wang, G., Yang, P., Yao, B., 2009. Diversity of beta-propeller phytase genes in the intestinal contents of grass carp provides insight into the release of major phosphorus from phytate in nature. Applied and Environmental Microbiology 75, 1508-1516.

Idriss, E.E., Makarewicz, O., Farouk, A., Rosner, K., Greiner, R., Bochow, H., Richter, T., Borriss, R., 2002. Extracellular phytase activity of Bacillus amyloliquefaciens FZB45 contributes to its plant-growth-promoting effect. Microbiology 148, 2097-2109.

Jackman, R.H., Black, C.A., 1951. Solubility of iron, aluminum, calcium, and magnesium inositol phosphates at different $\mathrm{pH}$ values. Soil Science 72, 179-186.

Jia, Y., Whalen, J.K., 2020. A new perspective on functional redundancy and phylogenetic niche conservatism in soil microbial communities. Pedosphere 30, 18-24.

Jorquera, M., Martínez, O., Maruyama, F., Marschner, P., de la Luz Mora, M., 2008. Current and future biotechnological applications of bacterial phytases and phytase-producing bacteria. Microbes and Environments 23, 182-191.

Jorquera, M.A., Saavedra, N., Maruyama, F., Richardson, A.E., Crowley, D.E., del C Catrilaf, R., Henriquez, E.J., de la Luz Mora, M., 2013. Phytate addition to soil induces changes in the abundance and expression of Bacillus $\beta$-propeller phytase genes in the rhizosphere. FEMS Microbiology Ecology 83, 352-360.

Jousset, A., 2012. Ecological and evolutive implications of bacterial defences against predators. Environmental Microbiology 14, 1830-1843.

Jurburg, S.D., Salles, J.F., 2015. Functional Redundancy and Ecosystem Function - The Soil Microbiota as a Case Study. IntechOpen, DOI: 10.5772/58981

Kerovuo, J., Rouvinen, J., Hatzack, F., 2000. Analysis of myo-inositol hexakisphosphate hydrolysis by Bacillus phytase: indication of a novel reaction mechanism. Biochemical Journal 352, 623-628.

Keshri, J., Yousuf, B., Mishra, A., Jha, B., 2015. The abundance of 
functional genes, $c b b L$, nifH, $a m o A$ and $a p s A$, and bacterial community structure of intertidal soil from Arabian Sea. Microbiological Research 175, 57-66.

Kim, O.H., Kim, Y.O., Shim, J.H., Jung, Y.S., Jung, W.J., Choi, W.C., Lee, H., Lee, S.J., Kim, K.K., Auh, J.H., Kim, H., Kim, J.W., Oh, T. K., Oh, B.C., 2010. $\beta$-propeller phytase hydrolyzes insoluble $\mathrm{Ca}(2+)$-phytate salts and completely abrogates the ability of phytate to chelate metal ions. Biochemistry 49, 10216-10227.

Lim, B.L., Yeung, P., Cheng, C., Hill, J.E., 2007. Distribution and diversity of phytate-mineralizing bacteria. ISME Journal 1, 321330.

Malusá, E., Sas-Paszt, L., Ciesielska, J., 2012. Technologies for beneficial microorganisms inocula used as biofertilizers. The Scientific World Journal 2012, 491206.

McLaren, T.I., Smernik, R.J., Simpson, R.J., McLaughlin, M.J., McBeath, T.M., Guppy, C.N., Richardson, A.E., 2015. Spectral sensitivity of solution 31P NMR spectroscopy is improved by narrowing the soil to solution ratio to $1: 4$ for pasture soils of low organic P content. Geoderma 257-258, 48-57.

Neal, A.L., Glendining, M.J., 2019. Calcium exerts a strong influence upon phosphohydrolase gene abundance and phylogenetic diversity in soil. Soil Biology \& Biochemistry 139, 107613.

Neal, A.L., Rossmann, M., Brearley, C., Akkari, E., Guyomar, C. Clark, I.M., Allen, E., Hirsch, P.R., 2017. Land-use influences phosphatase gene microdiversity in soils. Environmental Microbiology 19, 2740-2753.

Nicolaisen, M.H., Baelum, J., Jacobsen, C.S., Sørensen, J., 2008. Transcription dynamics of the functional $t f d A$ gene during MCPA herbicide degradation by Cupriavidus necator AEO106 (pRO101) in agricultural soil. Environmental Microbiology 10, 571-579.

Nicolaisen, M.H., Cuong, N.D., Herschend, J., Jensen, B., Loan, L.C., Du, V.P., Sorensen, J., Sorensen, H., Olsson, S., 2018. Biological control of rice sheath blight using hyphae-associated bacteria: development of an in planta screening assay to predict biological control agent performance under field conditions. BioControl 63, 843-853.

Oh, B.C., Chang, B.S., Park, K.H., Ha, N.C., Kim, H.K., Oh, B.H., Oh, T.K., 2001. Calcium-dependent catalytic activity of a novel phytase from Bacillus amyloliquefaciens DS11. Biochemistry 40, 9669 9676.

Oh, B.C., Choi, W.C., Park, S., Kim, Y.O., Oh, T.K., 2004. Biochemical properties and substrate specificities of alkaline and histidine acid phytases. Applied Microbiology and Biotechnology 63, 362-372.

Oh, B.C., Kim, M.H., Yun, B.S., Choi, W.C., Park, S.C., Bae, S.C., Oh T.K., 2006. $\mathrm{Ca}(2+)$-inositol phosphate chelation mediates the substrate specificity of beta-propeller phytase. Biochemistry 45 , 9531-9539.

Oliveros, J.C., 2007. An interactive tool for comparing lists with Venn Diagrams. http://bioinfogp.cnb.csic.es/tools/venny/index.html.

Otto, S., Harms, H., Wick, L.Y., 2017. Effects of predation and dispersal on bacterial abundance and contaminant biodegradation. FEMS Microbiology Ecology 93, fiw241.

Ragot, S.A., Kertesz, M.A., Mészáros, É., Frossard, E., Bünemann, E. K., 2017. Soil phoD and phoX alkaline phosphatase gene diversity responds to multiple environmental factors. FEMS Microbiology Ecology 93, fiw212.

Ramírez, C.A., Kloepper, J.W., 2010. Plant growth promotion by Bacillus amyloliquefaciens FZB45 depends on inoculum rate and P-related soil properties. Biology and Fertility of Soils 46, 835-844.

Raynaud, X., Nunan, N., 2014. Spatial ecology of bacteria at the microscale in soil. PLoS One 9, e87217.

Rengel, Z., Marschner, P., 2005. Nutrient availability and management in the rhizosphere: exploiting genotypic differences. New Phytologist 168, 305-312.

Richardson, A.E., Hadobas, P.A., 1997. Soil isolates of Pseudomonas spp. that utilize inositol phosphates. Canadian Journal of Microbiology 43, 509-516.

Richardson, A.E., Hadobas, P.A., Hayes, J.E., 2001. Extracellular secretion of Aspergillus phytase from Arabidopsis roots enables plants to obtain phosphorus from phytate. Plant Journal 25, 641649.

Rosenberg, K., Bertaux, J., Krome, K., Hartmann, A., Scheu, S., Bonkowski, M., 2009. Soil amoebae rapidly change bacterial community composition in the rhizosphere of Arabidopsis thaliana. International Society of Microbial Ecology Journal 3, 675-684.

Rousk, J., Bååth, E., 2011. Growth of saprotrophic fungi and bacteria in soil. FEMS Microbiology Ecology 78, 17-30.

Roy, N.K., Ghosh, R.K., Das, J., 1982. Monomeric alkaline phosphatase of Vibrio cholerae. Journal of Bacteriology 150, 1033-1039.

Sandberg, A.S., \& Ahderinne, R., 1986. HPLC method for determination of inositol, tri-, tetra-, penta-, and hexaphosphates in foods andintestinal contents. Journal of Food Science 51, 547-550.

Sanguin, H., Wilson, N.L., Kertesz, M.A., 2016. Assessment of functional diversity and structure of phytate-hydrolysing bacterial community in Lolium perenne rhizosphere. Plant and Soil 401, 151-167.

Shim, J.H., Oh, B.C., 2012. Characterization and application of calcium-dependent $\beta$-propeller phytase from Bacillus amyloliquefaciens DS11. Journal of Agricultural and Food Chemistry 60, 7532-7537.

Shin, S., Ha, N.C., Oh, B.C., Oh, T.K., Oh, B.H., 2001. Enzyme mechanism and catalytic property of beta propeller phytase. Structure (London, England) 9, 851-858.

Singh, J.S., Pandey, V.C., Singh, D.P., 2011. Efficient soil microorganisms: A new dimension for sustainable agriculture and environmental development. Agriculture, Ecosystems \& Environment 140, 339-353.

Stutter, M.I., Shand, C.A., George, T.S., Blackwell, M.S.A., Bol, R., Mackay, R.L., Richardson, A.E., Condron, L.M., Turner, B.L., Haygarth, P.M., 2012. Recovering phosphorus from soil: a root solution? Environmental Science \& Technology 46, 1977-1978.

Tang, J., Leung, A., Leung, C., Lim, B.L., 2006. Hydrolysis of precipitated phytate by three distinct families of phytases. Soil Biology \& Biochemistry 38, 1316-1324.

Turner, B.L., Papházy, M.J., Haygarth, P.M., McKelvie, I.D., 2002. Inositol phosphates in the environment. Philosophical Transactions of the Royal Society of London. Series B, Biological Sciences 357, 449-469. 
Turner, B.L., Richardson, A.E., Mullaney, E.J., 2007. Inositol phosphates: linking agriculture and the environment. Wallingford, UK; Cambridge, MA: CAB International.

Unno, Y., Okubo, K., Wasaki, J., Shinano, T., Osaki, M., 2005. Plant growth promotion abilities and microscale bacterial dynamics in the rhizosphere of Lupin analysed by phytate utilization ability. Environmental Microbiology 7, 396-404.

Valdespino-Castillo, P.M., Alcántara-Hernández, R.J., Merino-lbarra, M., Alcocer, J., Macek, M., Moreno-Guillén, O.A., Falcón, L.I., 2017. Phylotype dynamics of bacterial $p$ utilization genes in microbialites and bacterioplankton of a monomictic endorheic lake. Microbial Ecology 73, 296-309.

van der Bom, F., Magid, J., Jensen, L.S., 2019a. Long-term fertilisation strategies and form affect nutrient budgets and soil test values, soil carbon retention and crop yield resilience. Plant and Soil 434, 47-64.

van der Bom, F., Magid, J., Jensen, L.S., Long-term, P., 2017. Longterm $\mathrm{P}$ and $\mathrm{K}$ fertilisation strategies and balances affect soil availability indices, crop yield depression risk and $\mathrm{N}$ use. European Journal of Agronomy 86, 12-23.

van der Bom, F.J.T., McLaren, T.I., Doolette, A.L., Magid, J., Oberson, A., Frossard, E., Jensen, L.S., 2019b. Influence of long-term phosphorus fertilisation history on the availability and chemical nature of soil phosphorus. Geoderma 355, 113909. van der Bom, F.J.T., Nunes, I., Raymond, N.S., Hansen, V., Bonnichsen, L., Magid, J., Nybroe, O., Jensen, L.S., 2018. Longterm fertilisation form, level and duration affect the diversity, structure and functioning of soil microbial communities in the field. Soil Biology \& Biochemistry 122, 91-103.

von Wandruszka, R., 2006. Phosphorus retention in calcareous soils and the effect of organic matter on its mobility. Geochemical Transactions 7, 6-6.

Yan, Y., Li, W., Yang, J., Zheng, A., Liu, F., Feng, X., Sparks, D.L., 2014. Mechanism of myo-inositol hexakisphosphate sorption on amorphous aluminum hydroxide: spectroscopic evidence for rapid surface precipitation. Environmental Science \& Technology 48, 6735-6742.

Yebra, M.J., Zúñiga, M., Beaufils, S., Pérez-Martínez, G., Deutscher, J., Monedero, V., 2007. Identification of a gene cluster enabling Lactobacillus casei BL23 to utilize myo-inositol. Applied and Environmental Microbiology 73, 3850-3858.

Yoshida, K.I., Aoyama, D., Ishio, I., Shibayama, T., Fujita, Y., 1997. Organization and transcription of the myo-inositol operon, iol, of Bacillus subtilis. Journal of Bacteriology 179, 4591-4598.

Yousuf, B., Sanadhya, P., Keshri, J., Jha, B., 2012. Comparative molecular analysis of chemolithoautotrophic bacterial diversity and community structure from coastal saline soils, Gujarat, India. BMC Microbiology 12, 150. 